\title{
Assessment of Mitigation Strategies for Tropospheric Phase Contributions to InSAR Time-Series Datasets over Two Nicaraguan Volcanoes
}

\author{
Kirsten J. Stephens ${ }^{1, *(D)}$, Christelle Wauthier ${ }^{1,2}{ }^{\oplus}$, Rebecca C. Bussard ${ }^{1, \dagger}$, Machel Higgins $^{1}$ and \\ Peter C. LaFemina ${ }^{1}$ (D) \\ 1 Department of Geosciences, The Pennsylvania State University, University Park, PA 16802, USA; \\ cuw25@psu.edu (C.W.); rbussard@uoregon.edu (R.C.B.); mhh16@psu.edu (M.H.); pcl11@psu.edu (P.C.L.) \\ 2 The Institute for Computational and Data Sciences, The Pennsylvania State University, University Park, \\ PA 16802, USA \\ * Correspondence: kjs51@psu.edu \\ $+\quad$ Now at: Department of Earth Sciences, University of Oregon, Eugene, OR 97403-1272, USA.
}

Received: 17 December 2019; Accepted: 26 February 2020; Published: 1 March 2020

\begin{abstract}
Interferometric Synthetic Aperture Radar (InSAR) studies of ground displacement are often plagued by tropospheric artifacts, which are phase delays resulting from spatiotemporal variations in the refractivity of air within the troposphere. In this study, we focus on COSMO-SkyMed (X-band) InSAR products obtained over two different types of volcanoes in Nicaragua: the Telica stratovolcano and the Masaya caldera. We examine the applicability of an empirical linear correction method and three Global Weather Models (GWMs) with different spatial and temporal resolutions for removing the tropospheric phase component. We linearly invert the tropospheric-corrected interferograms using the Small BAseline Subset (SBAS) time-series technique to produce time-series of ground displacement. Statistical assessments were performed on the corrected interferograms to examine the significance of the applied corrections on the individual interferograms and time-series results. We find that the applicability of the correction methods is highly case-dependent and that in general, the temporal resolution of GWMs influences their ability to capture turbulent tropospheric phase delays. At the two target volcanoes, our study shows that none of the GWMs are able to accurately capture the tropospheric phase delays. Our study provides a guide for researchers using InSAR data in tropical regions who wish to use tropospheric model corrections to carefully assess the applicability of the different types of tropospheric correction methods.
\end{abstract}

Keywords: InSAR; tropospheric effects; time-series analysis; global weather models; tropical region; Nicaragua; volcano

\section{Introduction}

Interferometric Synthetic Aperture Radar (InSAR) is a technique that combines repeat SAR satellite acquisitions to image ground displacement over specific regions of the Earth [1]. Over the past 25 years, InSAR has been used to examine ground displacement in active volcanic regions [2,3], allowing for an improved understanding of the extent of the storage and transport of magma in magma plumbing systems [4-6], as well as volcanic edifice growth and stability [7-11].

The total displacement field at each pixel $(\Delta \phi)$ obtained from radar interferometry is a function of a number of different contributions [2,12]:

$$
\Delta \phi=\Delta \phi_{\text {def }}+\Delta \phi_{\text {orbit }}+\Delta \phi_{\text {topo }}+\Delta \phi_{\text {atm }}+\Delta \phi_{\text {noise }}
$$


which include the true displacement of the ground $\left(\Delta \phi_{d e f}\right)$, differences in the orbital geometry of the satellite $\left(\Delta \phi_{\text {orbit }}\right)$, contributions of the topography $\left(\Delta \phi_{\text {topo }}\right)$, phase delay contributions from the ionosphere and troposphere $\left(\Delta \phi_{a t m}\right)$, and other noise contributions such as instrument noise and changes in scattering properties of the ground $\left(\Delta \phi_{\text {noise }}\right)$. Topographic contributions can be accounted for by using digital elevation models [13] and orbital geometry contributions can be removed using precise satellite orbits (also known as flattening). With the improvement in satellite technology, thermally-correlated noise contributions from the instruments onboard the satellites can be assessed $[14,15]$. Poor coherence (low signal-to-noise ratio) pixels due to changes in the scattering properties of the ground can be masked from the ground displacement field.

Atmospheric contributions, however, are more difficult to account for as they often involve phase delay contributions from both the ionosphere $(60-1000 \mathrm{~km})$ and troposphere $(0-10 \mathrm{~km})$, which can bias true ground displacement measurements [12,16]. Ionization of neutral atoms and molecules in the ionosphere from high energy solar radiation results in a mix of neutral gas molecules, free ions and electrons [17]. This influences the propagation of microwave radiation through the ionospheric layer, causing phase shifts such as phase advances and group delays, which translate as azimuth shifts and defocusing between SAR acquisitions $[17,18]$. Ionospheric effects have a significant impact on SAR satellite imagery acquired using longer wavelength radiation, such as L-band $(\sim 24 \mathrm{~cm})$, compared to the shorter wavelengths, such as C-band $(\sim 6 \mathrm{~cm})$ and X-band $(\sim 3 \mathrm{~cm})$ [18]. On the other hand, tropospheric air refractivity gradients are a function of temperature, pressure, and water vapor, and all vary vertically as a function of height in the atmosphere $[13,19]$. Water vapor also varies laterally between radar satellite acquisition times, regardless of the terrain, and thus influences the 3D spatial refractivity within the troposphere [12]. Spatial and temporal changes in the relative humidity of $\sim 20 \%$ can result in up to $10 \mathrm{~cm}$ of error in InSAR ground displacement maps [20]. Phase delays that vary temporally and spatially in the troposphere are referred to as turbulent phase delays and are the result of turbulent mixing processes within the troposphere such as convection due to solar heating of the Earth's surface, frictional drag, changes in wind direction and velocity at different pressure levels, and seasonal variations in water vapor, temperature and pressure conditions [12,13]. Stratified phase delays are typically associated with topography as concentric fringes centered over topographic features $[12,19]$. Tropospheric phase delays are independent of radar satellite wavelength as the troposphere is a non-dispersive medium [21]. However, there have been cases where large-scale intense precipitation events were detected in X- and C-band SAR imagery [22].

Different approaches have been used to account for and remove tropospheric phase delays. Empirical methods involve estimating the path delay from the processed interferogram itself using different relations. One estimation for tropospheric phase delays $\left(\Delta \phi_{\text {tropo }}\right)$ can be performed by assuming a linear relation between the topography of the region and the phase of a region not experiencing ground displacement [23-27]. This method has proven effective in reducing tropospheric contributions to phase values but does not account for the lack of spatial variability over different sections of the interferograms. A recent development uses a power law model for tropospheric phase delay to correct for these limitations by using a gradient that varies spatially from acquisition to acquisition [28]. The power law method can reduce spatially varying tropospheric delays but is limited to estimating and reducing delays that fit a power law. While both the power law and linear corrections attempt to remove topography correlated phase delay, other factors such as the turbulent component delay that arises from irregular air motions in 3D space are not accounted for by these corrections $[27,29]$.

Predictive methods estimate turbulent and stratified phase delays using external datasets, such as Global Positioning System (GPS) zenith delay estimates [30], data assimilation of weather reanalysis datasets [21,31-36], locally collected atmospheric datasets [27,37], multi-spectral estimates of water vapor [27,38,39], and mesoscale data assimilation models [40-42], or a combination [43,44]. Global Weather Models (GWMs) cover large regions of Earth and provide variables such as temperature, relative and specific humidity, and pressure at multiple heights within the atmosphere [33]. Several 
different GWMs have been used to remove tropospheric contributions from InSAR datasets, such as the North American Regional Reanalysis (NARR) [29,31,34,35,45,46], the Modern-Era Retrospective Analysis for Research and Applications (MERRA) [29,33,39], the Moderate Resolution Imaging Spectroradiometer (MODIS) [29,38,39,43], and weather reanalysis outputs from the European Centre for Medium-Range Weather Forecasts (ECMWF): ERA40 [25,31], ERA-Interim (ERA-I) [27,29,32-34, 36,46,47], ERA5 [21,47,48], high-resolution ECMWF (hereafter HRES ECMWF) [21,29,44,49-53], and operational analysis [31]. From the GWMs, tropospheric phase delay maps that incorporate estimates of both the wet and dry phase delays can be created. There are a number of pros and cons associated with the application of these phase delay maps to ground displacement maps. For example, GWM-derived phase delay maps have been shown to remove stratified phase delays, improve phase unwrapping, and reduce biases in velocity field estimates when performing time-series analysis [33,53]. However, weather models are highly dependent on the initial conditions of the observed input data, the model physics and assumptions used, spatial and temporal resolutions, and local data assimilation in the region of interest, all of which influence the reliability of the output atmospheric variables [32,40].

Previous InSAR studies involving different tropospheric empirical and predictive correction methods have shown that the effectiveness of the methods vary from site-to-site [27,31]. NARR, which only spans North America to northern South America, has shown a variation in success depending on the region of study and the topography. Volcanic arc studies across the Cascades region in the U.S. have shown that NARR was able to capture stratified delays well at Lassen Volcanic Center but not at Medicine Lake Volcano [34], and had good agreement with interferograms spanning the Lake Mead area [31], but was outperformed by ERA-I at Mount Saint Helens [46]. Along CAVA, studies over Colima and Popocatepetl volcanoes demonstrated that NARR had good agreement with MERIS data in $70 \%$ of the interferograms studied [45]. Another study demonstrated that NARR performed well over the Big Island of Hawaii compared to ERA-I, but was not able to capture turbulence over the Parkfield region in California [33]. A few studies have been published using the recently released ECMWF ERA5 dataset. ERA5 was shown to perform well over the islands of Tenerife and Almeria in Spain, and the island of Crete in Greece [48], but was outperformed by the power-law empirical relation in the region of Kyrgyzstan [47]. A study incorporating interferograms spanning Oklahoma in the Central U.S. and south central Mexico demonstrated that a combination of GPS-derived corrections (when and where available) and HRES ECMWF outputs (obtained through the Generic Atmospheric Corrections Online Service for InSAR, GACOS [44]) provide the optimum mitigation approach compared to NARR, ERA-I and the empirical linear relation [29]. Studies testing the applicability of recently released ECWMF datasets have also shown variation in success. ERA5 and GACOS were shown to perform equally well in landslide-prone regions in China, reducing the root-mean-square in $62-71 \%$ of interferograms [21]. Studies in volcanic regions have shown that GACOS captured broad atmospheric phase delays along the coastline of Bali Island in Indonesia and reduced the variance between 35-45\% in interferograms spanning Bali Island in Indonesia [49], as well as improved upon previous estimates of ground displacement velocities at Agung volcano [53]. GACOS was also shown to reduce the standard deviation by at least $20 \%$ in $45 \%$ of the interferograms spanning the Usu volcano in Japan [51]. However, application of GACOS phase delays to interferograms spanning Cerro Azul volcano in the Galapagos showed that the standard deviations of the corrected interferograms were not significantly reduced and thus were not useful for further geodetic modeling [50]. A study in southern California showed that while GACOS improved the accuracy of InSAR time-series results overall, it was not able to capture turbulent phase delays [52]. A more recent study has shown that an approach combining GACOS and a linear empirical method resulted in improved estimates of stratified and turbulent phase delay over Agung volcano [54].

In this paper, we focus on the assessment of strategies used to account for stratified and turbulent tropospheric contributions in COSMO-SkyMed (CSK) X-band InSAR time-series datasets for two volcanic regions in Nicaragua, Telica and Masaya, that are heavily affected by seasonal weather conditions. The short wavelength of X-band $(3.1 \mathrm{~cm})$ is not greatly affected by perturbations in the 
ionosphere, and thus we neglect ionospheric contributions [12]. We first discuss the processing steps taken to create the InSAR ground displacement maps, perform time-series analysis, and application of the tropospheric phase delay mitigation methods. Finally, we test the applicability of these approaches for estimating tropospheric phase delay contributions to InSAR ground displacement maps and time-series results for two case study volcanoes from Nicaragua, Telica stratovolcano and Masaya caldera. We evaluate the effectiveness of the different tropospheric phase delay correction methods at each volcano quantitatively using different statistical approaches and qualitatively using in-situ continuous GPS measurements.

\section{Methods}

\subsection{InSAR Time-Series Analysis}

For both case study regions in Nicaragua, the InSAR technique was applied to data obtained from the Italian Space Agency X-band $(3.1 \mathrm{~cm})$ CSK constellation of four satellites, which has a temporal resolution ranging between 1-14 days and a spatial resolution of $3 \mathrm{~m}$ in range and azimuth. Potential date pairs for creating interferograms were examined by plotting the perpendicular baseline versus radar satellite acquisition date. The first acquisition date was set to zero baseline, and a perpendicular baseline threshold of less than $300 \mathrm{~m}$ and temporal threshold of less than 180 days were used to determine which interferogram pairs to make. Each perpendicular baseline versus radar satellite acquisition date plot was examined for network connectivity and baseline separations, which is important when using the Small BAseline Subset (SBAS) time-series analysis technique $[55,56]$. A well-connected network is defined as a perpendicular versus temporal baseline plot in which each date has at least two interferogram pairs associated with it. Interferograms were processed using the GAMMA software [57], and a $12 \mathrm{~m}$ spatial resolution TanDEM-X digital elevation model was used to remove topographic phase contributions $[58,59]$. The interferograms were smoothed using an adaptive spectral filter [60] and unwrapped using the minimum cost flow technique and triangular irregular network [61]. The unwrapped interferograms were then converted from radar Line-Of-Sight (LOS) phase in radians to LOS ground displacement in centimeters with respect to the ground. The interferograms were then downsampled from $12 \mathrm{~m}$ to $90 \mathrm{~m}$ pixel spacing for consistency between the different GWM datasets (see Section 2.3 for further details) and re-referenced to a region assumed to experience little to no displacement. Individual downsampled interferograms were examined for unwrapping errors, and coherence within the vicinity of each case study volcano and regions that would be used as reference regions. Prior to time-series analysis, a coherence threshold of 0.3 was used to mask noisy pixels in each interferogram.

The SBAS time-series technique is a pixel-by-pixel linear least squares inversion method that determines the LOS ground displacement between each acquisition date for each pixel $[55,56]$. The first acquisition date was set to zero as a reference. Locations for time-series plots were chosen according to the locus of activity at each case study volcano, coherence, and/or locations of continuously operating GPS stations. InSAR time-series errors were calculated using the standard deviation of the chosen plotted time-series region.

As a form of validation tool, we used a single GPS station at each case study location to assess the variability in the time-series results after performing the different tropospheric phase delay corrections. All GPS data were processed using the GISPY-OASIS 6.4 software with clock and orbit products developed by the Jet Propulsion Laboratory to estimate the daily ground motion. Daily static positions were calculated using the Precise Point Positioning method [62]. Phase ambiguity resolution was performed using the single receiver algorithm [63]. Ocean loading corrections were applied using FES2004 [64]. Wet and dry tropospheric zenith delay were modeled with VMF1 mapping functions [65]. Final solutions were transformed into the IGb08 reference frame [66]. We note here that the GPS time-series data have not been corrected for any hydrologic loading-unloading of the ground. The 
horizontal and vertical components of the GPS time-series data were then converted into the LOS of the satellite using the following equation [67]:

$$
U_{L O S}=\left[U_{N} \sin \varnothing-U_{E} \cos \varnothing\right] \sin \theta+U_{z} \cos \theta
$$

where $U_{N}$ and $U_{E}$ are the north-south and east-west horizontal components, and $U_{Z}$, the vertical component of the ground displacement field, respectively. $\varnothing$ is the azimuth of the satellite heading vector (positive clockwise from North), and $\theta$ is the incidence angle of the satellite.

\subsection{Linear Stratified Correction}

For this study, we used a simple empirical linear relation to examine the difference in topography-correlated stratified phase delay between volcanoes with and without significant topographic features. The linear relation is estimated between the topography of the region $(h)$ and the phase of a region not experiencing displacement $\left(\Delta \phi_{0}\right)[23,24,27]$ :

$$
\Delta \phi_{\text {tropo }}=K_{\Delta \phi} h+\Delta \phi_{0}
$$

where $\Delta \phi_{0}$ is a constant value that applies shifts in the phase over the entire interferogram, and $K_{\Delta \phi}$ is the phase slope. Using this equation, the linear phase delay maps were obtained by estimating the phase constant in radians and the phase slope in radians per meter for each unwrapped interferogram in radar coordinates [57]. The corrected unwrapped interferogram in radar coordinates was then obtained by subtracting the linear phase delay map in radar coordinates from the original unwrapped interferogram. The corrected interferogram was then converted into geographic coordinates for further analysis.

\subsection{Global Weather Models (GWMs)}

We selected GWMs using the following criteria: geographic coverage over Nicaragua, spatial resolution less than $35 \mathrm{~km}$, and temporal resolution of $6 \mathrm{~h}$ or less. Three GWMs were selected for testing (Table 1, Figure S3): (1) NARR dataset, (2) ERA5 reanalysis dataset, and (3) HRES ECMWF products (accessible through GACOS). The model times from the GWMs were selected such that they were within half an hour of the descending (23:30 UTC acquisition time, 00:00 UTC model time) Telica and ascending (11:40 UTC acquisition time, 12:00 UTC model time) Masaya CSK acquisitions. Temporal interpolation between subsequent model times was not performed, except for the HRES ECMWF dataset which are linearly interpolated temporally using the acquisition time through GACOS. The NARR and ERA5 datasets are generated using the concept of data reanalysis in which previous forecasts are re-assessed using more recent atmospheric observations so that an improved forecast can be generated. In the raw GWM data, any pressure levels below that of the grid node local elevations are extrapolations. All GWMs are freely available online, except for HRES ECMWF which is accessible either through GACOS or a personal license.

Table 1. Selected Global Weather Models (GWMs) and corresponding information.

\begin{tabular}{cccc}
\hline GWMs & Spatial Resolution & Temporal Resolution & Vertical Resolution \\
\hline NARR & $0.3^{\circ} \times 0.3^{\circ}$ & $3 \mathrm{~h}(00,03,06,09,12$, & 29 levels $(1000-100 \mathrm{hPa})$ \\
ERA5 & $(32 \mathrm{~km})$ & $15,18,21)$ & \\
& $0.281^{\circ} \times 0.281^{\circ}$ & Hourly & 37 levels $(1000-1 \mathrm{hPa})$ \\
HRES ECMWF & $(30 \mathrm{~km})$ & & \\
(GACOS $)$ & $\left(125^{\circ} \times 0.125^{\circ}\right.$ & $6 \mathrm{~h}(00,06,12,18)$ & 137 levels $(1000-0.01 \mathrm{hPa})$ \\
\hline
\end{tabular}

NARR is a product from the National Centers for Environmental Prediction- National Center for Atmospheric Research (NCEP-NCAR), and extends across North America, the Caribbean, Central 
America, and the northern tip of South America [68]. The model is produced using 3D variational data assimilation where the previous 3-h forecast is used as the first guess for the next forecast cycle [69]. NARR was developed as a follow-up dataset to the NCEP-DOE Global Reanalysis, with improved temporal and spatial resolutions due to the increase in the number and quality of observations being assimilated, and improvements within the assimilation model itself [68]. For this study, we used NARR outputs for temperature $(\mathrm{K})$, specific humidity and geopotential height $\left(\mathrm{m}^{2} \mathrm{~s}^{-2}\right)$ defined at 29 pressure levels (1000-100 hPa).

ERA5 is the fifth generation of the ECMWF atmospheric reanalysis model of the global climate [70,71]. The model is produced using 4D variational data assimilation of 12-h windows and is then time-stepped at 12-min intervals for the high-resolution data. Compared to the previous ECMWF reanalysis dataset ERA-Interim, which has a 6-h temporal interval and a spatial resolution of $80 \mathrm{~km}$, ERA5 has improved hourly temporal resolution and a spatial resolution of $30 \mathrm{~km}$. We used ERA5 outputs for relative humidity (\%), temperature, and geopotential height defined at 37 pressure levels (1000-1 hPa).

HRES ECMWF is an operational numerical weather model available through the ECMWF (https://www.ecmwf.int/en/forecasts/datasets/set-i) with a spatial resolution of $14 \mathrm{~km}$ and temporal resolution of $6 \mathrm{~h}$. The output is a single prediction that provides forecasts to 10 days using observations, prior information about the Earth systems, and the highest resolution model available at ECMWF. We requested data through GACOS (http://ceg-research.ncl.ac.uk/v2/gacos/), which obtains the HRES ECMWF variables for relative humidity, temperature and geopotential defined at 137 pressure levels (1000-0.01 hPa).

We followed the same techniques as described by Jolivet et al. [32] and Parker et al. [34] to create tropospheric total delay phase maps from the ERA5 and NARR datasets. In order to apply the delay phase maps to the satellite radar datasets, the zenith total delay at each pixel was converted into the slant total delay $\left(\partial_{L O S}^{i}\right)$ using the satellite incidence angle $(\theta)[31,72]$ :

$$
\partial_{L O S}^{i}=\partial_{H D}^{i}+\partial_{W D}^{i}=\frac{10^{-6}}{\cos \theta}\left[\frac{k_{1} R_{d}}{g_{0}}\left(P\left(z_{0}\right)-P\left(z_{r e f}\right)\right)-\int_{z_{0}}^{z_{r e f}}\left(\left(k_{2}-k_{1} \frac{R_{d}}{R_{v}}\right) \frac{P_{H_{2} O}}{T}+k_{3} \frac{P_{H_{2} O}}{T^{2}}\right) d z\right]
$$

The equation is split into the hydrostatic delay $\left(\partial_{H D}^{i}\right)$ and the wet delay $\left(\partial_{W D}^{i}\right)$ terms. P is the pressure at the ground level $\left(\mathrm{z}_{0}\right)$ and at reference height $\left(\mathrm{z}_{\mathrm{ref}}\right), \mathrm{T}$ is the temperature, $P_{\mathrm{H}_{2} \mathrm{O}}$ is the partial pressure of water vapor, and $g_{0}$ is the gravitational acceleration at ground level. $k_{1}, k_{2}, k_{3}$ represent laboratory-derived atmospheric refractivity constants (see Table 2) [73]. A reference height of $15 \mathrm{~km}$ was chosen for both ERA5 and NARR as the changes in water vapor above this height are assumed to be negligible [12,21]. Constants $R_{d}$ and $R_{\mathrm{V}}$ are the specific gas constants for dry air and water vapor respectively (see Table 2). A TanDEM-X digital elevation model with a resolution of $12 \mathrm{~m}$ was used to horizontally interpolate the slant total delay vertical profiles from the original spatial resolutions as given in Table 1 . This procedure allows the final delay maps to extract the vertically integrated atmospheric properties for each pixel elevation at the spatial resolution of the digital elevation model [29]. Each slant total delay map was then downsampled to $90 \mathrm{~m}$ and re-referenced to the same location as the uncorrected interferogram datasets. The resulting 2D tropospheric total delay map is in centimeters and corresponds to each satellite acquisition date.

Table 2. Values corresponding to constants used in the Equation (4) for the slant total delay [32,73].

\begin{tabular}{cc}
\hline Variable & Values \\
\hline$k_{1}$ & $0.776 \mathrm{~K} \cdot \mathrm{Pa}^{-1}$ \\
$k_{2}$ & $0.716 \mathrm{~K} \cdot \mathrm{Pa}^{-1}$ \\
$k_{3}$ & $3750 \mathrm{~K}^{2} \cdot \mathrm{Pa}^{-1}$ \\
$R_{d}$ & $287.05 \mathrm{~J} \cdot \mathrm{kg}^{-1} \cdot \mathrm{K}^{-1}$ \\
$R_{v}$ & $461.495 \mathrm{~J} \cdot \mathrm{kg}^{-1} \cdot \mathrm{K}^{-1}$ \\
\hline
\end{tabular}


The HRES ECMWF zenith total delay maps output by GACOS are created using a similar procedure, with a few exceptions: a reference height of $80 \mathrm{~km}$, horizontal interpolation to the $90 \mathrm{~m}$ Shuttle Radar Topography Model digital elevation model, and an Iterative Tropospheric Decomposition (ITD) approach to decouple stratified and turbulent phase delays and interpolate the zenith total delay maps $[74,75]$. The zenith total delay maps were then converted to the slant total delay with respect to the ground using the satellite incidence angle at each pixel (see Equation (4)).

In order to correct for tropospheric phase delays in the InSAR displacement maps, the total delay map corresponding to the slave SAR acquisition date was subtracted from the total delay map master SAR acquisition date to create the interferogram total delay map. The corrected interferograms were then obtained by subtracting the interferogram total delay map from the unwrapped InSAR ground displacement map.

\subsection{Statistical Assessments}

Empirical and predictive tropospheric phase delay methods are widely used in InSAR ground displacement studies; however, it is important to assess the results of these corrections before using the corrected ground displacements for further analysis and modelling. In the absence of a dense network of validation datasets, such as GPS, it is unfeasible to determine a priori whether a correction method will work or not [54]. Thus we first apply the different correction methods over our two case study volcanoes in Nicaragua before we assess the quality of the corrections. Prior to any statistical analyses, all interferograms were re-referenced to the same region specific to each volcano case study area, and pixels with a coherence threshold of less than 0.3 were masked out to avoid assessing noisy pixels. Unless stated otherwise, regions of ground displacement or potential ground displacement at each case study volcano were also masked out in order to avoid ground displacement events biasing the results. No orbital ramps were removed as this allowed us to assess the ability of each mitigation technique to account for tropospheric phase delays on broad and local scales [29].

Phase-elevation relationships provide a graphical interpretation of the spread of the LOS phase versus elevation for each pixel in a single interferogram, where a coefficient of determination $\left(R^{2}\right)$ greater than 0.1 (equivalent to a correlation coefficient of $\sim 0.3$ ) suggests that there are stratified tropospheric components present within the scene $[33,34,45]$. Overlaying the phase-elevation for the tropospheric total delay maps against its respective uncorrected interferogram gives an indication of whether or not the total delay map is capturing LOS phase due to tropospheric phase delays within an uncorrected interferogram [33]. We computed $\mathrm{R}^{2}$ for each uncorrected interferogram and associated total phase delay maps for each tropospheric phase delay method. In addition, we also visually assessed the phase-elevation relationships of the full CSK scenes between the uncorrected interferograms and the total delay maps for each tropospheric phase delay method for all case study interferograms in terms of the trend in the plot (i.e., the slope) and the spread in the LOS phase.

Computation of the variance (or equivalently the standard deviation) is commonly performed to assess the ability of the tropospheric mitigation techniques to reduce the atmospheric noise within an interferogram [21,29,32-34,48-50,52]. In lieu of a dense GPS network, variance reduction results have shown to be good indicators of the performance of the correction methods [54]. For each uncorrected and corrected interferogram, we computed the corresponding variance for the entire interferogram, and the variance reduction $\left(\sigma_{\text {red }}^{2}\right)$ which examines the change in variance between the uncorrected $\left(\sigma_{\text {uncorrected }}^{2}\right)$ and corrected interferograms $\left(\sigma_{\text {corrected }}^{2}\right)[33]$ :

$$
\sigma_{\text {red }}^{2}(\%)=\left(\frac{\sigma_{\text {uncorrected }}^{2}-\sigma_{\text {corrected }}^{2}}{\sigma_{\text {uncorrected }}^{2}}\right) \times 100
$$

A positive variance reduction means that the variance of the corrected interferogram is less than that of the uncorrected interferogram, while a negative variance reduction means that the variance of the corrected interferogram is greater than that of the uncorrected interferogram. 
In addition to these statistical assessments, we also computed semivariogram structure functions to examine the atmospheric noise structure within the interferograms. More details on this method, and corresponding results for both case study regions, can be found in the Supplementary Material.

Time-series results were examined visually with each other as well as with the GPS LOS data, and also quantitatively by computing the variance of each InSAR time-series dataset when the relationship between the different time-series results were not clearly observed visually.

\section{Case Studies}

The Central American Volcanic Arc (CAVA) is well-known in the geodetic community to have significant tropospheric phase delay contributions to the observed ground displacement field [35,76,77]. Telica and Masaya were selected as case studies due to their current high levels of activity and different edifice topography. According to the Köppen-Geiger climate classification, both Telica and Masaya are located within tropical climates [78]. However, the amount of precipitation between these two locations is different, even though they are only $100 \mathrm{~km}$ apart. Telica is close to the border between a tropical monsoon and a tropical rainforest climate, while Masaya is located within a tropical savannah region that typically receives less rain in the driest summer month compared to both the monsoon and rainforest regions. Both volcanoes experience seasons of high moisture and humidity and therefore the presence of stratified and turbulent water vapor is very likely [77]. As Telica and Masaya are active volcanoes nearby to thousands of Nicaraguan inhabitants, it is critical to obtain accurate estimates of ground displacement for volcano-related hazards assessment.

\subsection{Telica Volcano}

\subsubsection{Background}

Telica Volcano $(1036 \mathrm{~m})$ is a basaltic andesitic stratovolcano-volcanic complex located in western Nicaragua $(12.6058 \mathrm{~N}, 86.8422 \mathrm{~W})$ and consists of several cones and vents in an E-W alignment (Figure 1) [79,80]. The volcanic complex is located within the Maribios Range of the CAVA. Telica is a persistently active volcano, exemplified by high rates of seismic unrest, high-temperature fumaroles, and high fluxes of volcanic gases [80,81]. The persistent activity is punctuated by Volcanic Explosivity Index 1-2 phreatic explosions on 1-5-year time scales, with Volcanic Explosivity Index $>2$ events on decadal scales. A geophysical monitoring network was installed on Telica from 2009-2016 [80,81], and consisted of 6 broadband seismometers and ten continuously operating GPS stations. In 2015, Telica entered a new phase of explosive activity that consisted of three main phases: (1) 23 April- 8 June, (2) 23-29 September, and (3) 22-29 November [81]. During this eruptive period, the stations closest to the active crater (i.e., TECF and TELN) were running, as was the station $15 \mathrm{~km}$ from the volcano, JECF.

\subsubsection{Telica InSAR Dataset}

We obtained 60 descending CSK images over Telica, spanning 7 December 2014 until 26 December 2015. Following the criteria for coherence within the Telica region and neighboring regions within $\sim 10-12 \mathrm{~km}$, and network connectivity of potential interferogram pairs, 199 interferograms were created from 50 CSK acquisitions (Figure S1). These CSK scenes have regions of very steep topography, resulting in a higher probability of stratified tropospheric phase delays, as well as turbulent phase delays due to the border between the rainforest and monsoon tropical climates.

\subsubsection{Tropospheric Phase Delay Correction Results}

Below, we present the phase-elevation and variance reduction statistical assessment results for the application of the tropospheric correction methods to the CSK Telica interferograms, following the details given in Section 2.4. For the statistical assessments, the whole edifice of Telica was masked out in order to remove any potential volcano-related displacement that would bias the assessments of the atmospheric noise within the interferogram as a whole. 


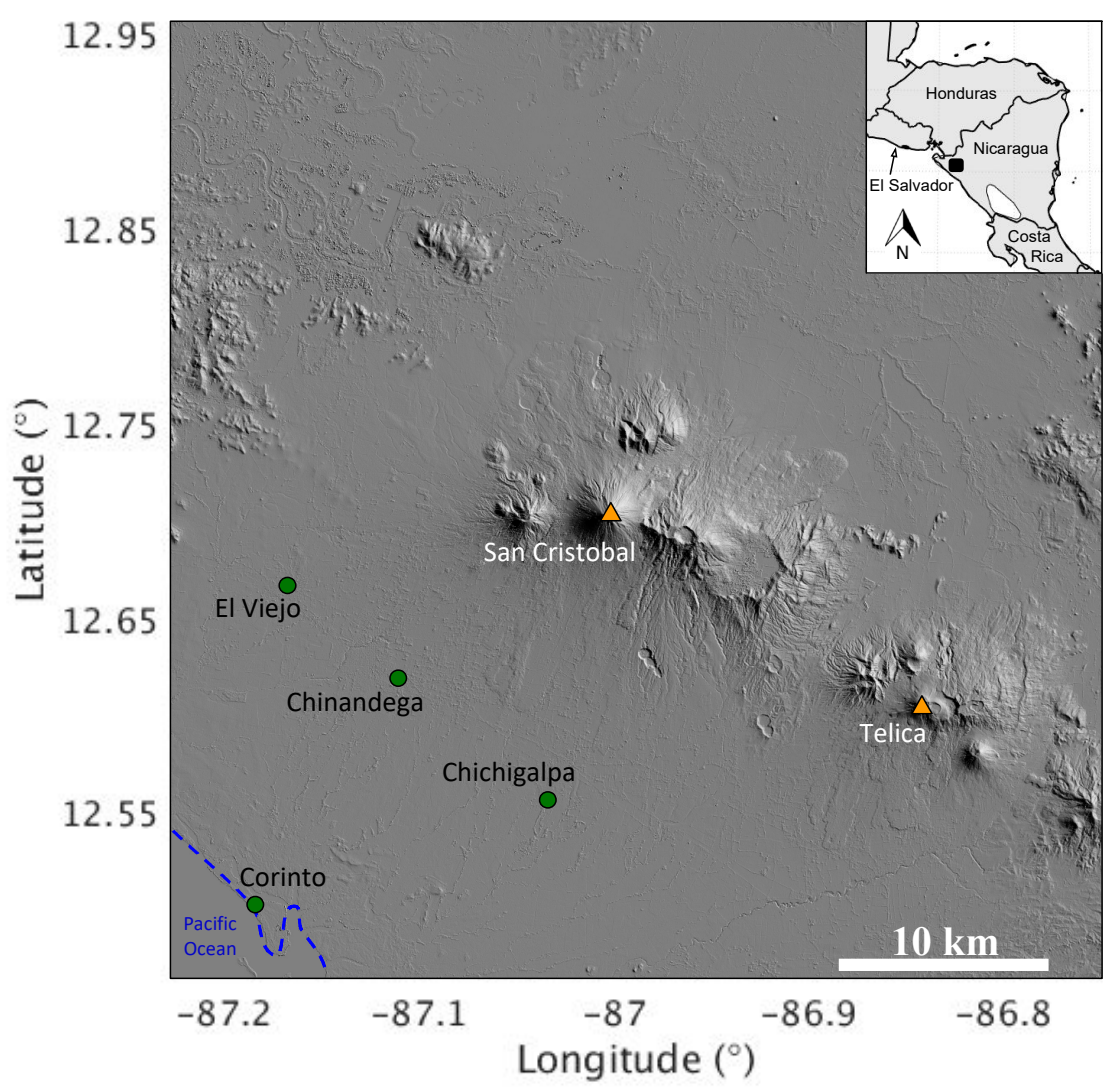

Figure 1. Hillshade topography image obtained using the TanDEM-X digital elevation model of Telica volcano. Orange triangles indicate Holocene volcanoes [82] and nearby towns with populations greater than 10,000 are indicated with green circles [83]. The Pacific coastline is indicated by the blue dashed line. Inset image indicates the location of the descending CSK scene in Nicaragua.

Phase-Elevation Plots

Overall, we observe a variation in the agreement between the total phase delay maps with respect to the uncorrected interferograms in the phase-elevation plots. An example is given in Figure 2, where the total delay maps, corrected interferograms, and phase-elevation relationships are plotted for a single interferogram pair (20150217-20150516). Visually, it appears that none of the tropospheric total delay maps match the unwrapped interferogram in terms of spatial patterns and magnitude of LOS phase (Figure 2a-e). The linear total delay map shows distinct negative LOS phase change patterns over both San Cristobal and Telica volcanoes, with positive LOS phase change in the remaining regions of the total delay map (Figure $2 b$ ). The ERA5 and NARR total delay maps look fairly similar to each other in terms of LOS phase and spatial patterns, while the GACOS total delay map has the greatest range in LOS phase values and predicts a large LOS phase pattern over San Cristobal volcano $(\sim 10 \mathrm{~cm})$ (Figure 2c-e). Differences between the total delay maps and corrected interferograms are more obvious in the phase-elevation plots (Figure 2j-m). The GACOS total delay has the greatest range in LOS phase compared to both the ERA5 and NARR datasets, but does not capture the same shape and range in LOS as that of the uncorrected interferogram phase-elevation plot (Figure $2 \mathrm{k}-\mathrm{m}$ ). Of all the tropospheric correction methods, the linear total delay map has the smallest range in LOS phase, although it does appear to capture the general trend of the uncorrected interferogram's phase-elevation relationship (Figure 2j). The ERA5 total delay map captures the uncorrected interferogram phase-elevation pattern best, followed by NARR. 

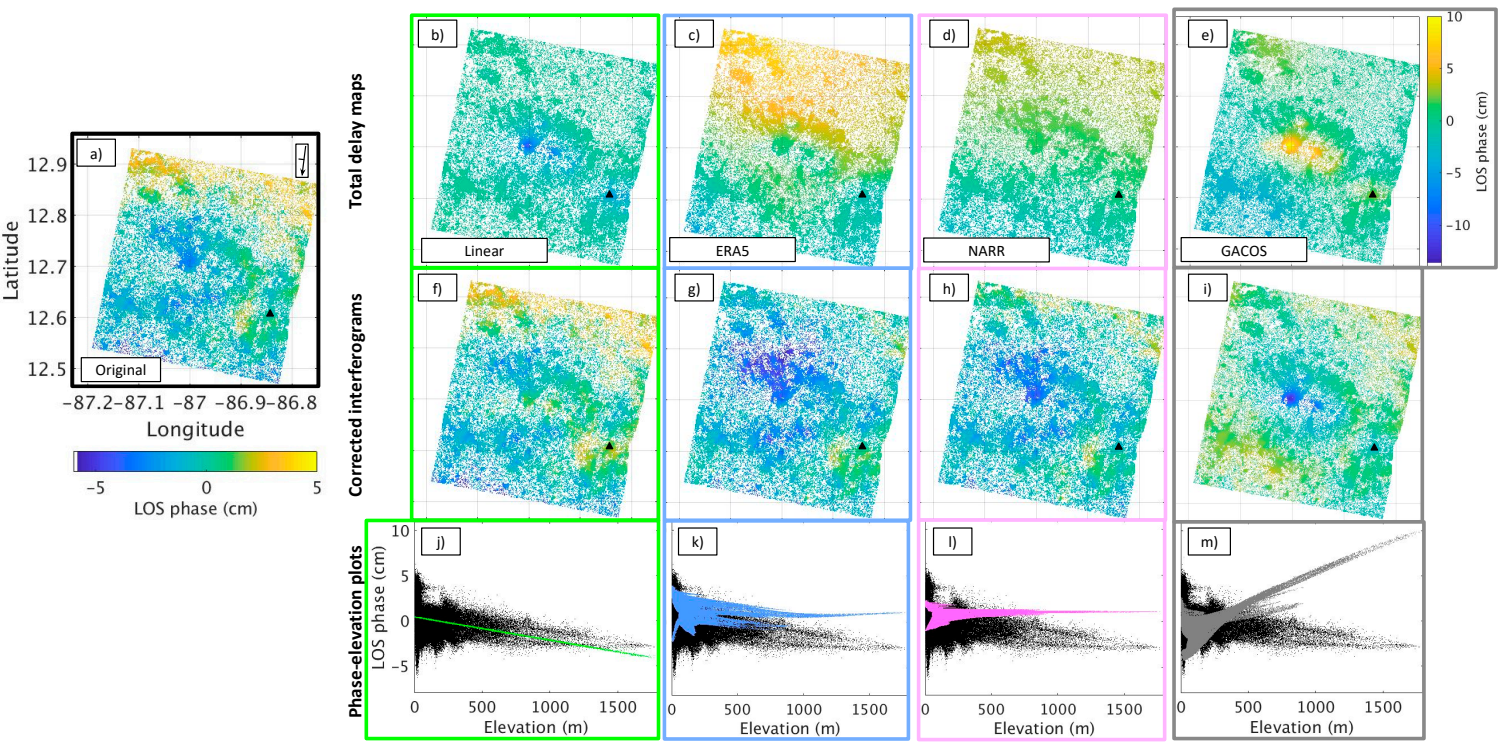

Figure 2. Comparison of the different tropospheric phase delay correction methods for Telica unwrapped interferogram 20150217-20150516. (a) Uncorrected interferogram, (b-e) Total tropospheric delay map for each correction method, $(\mathbf{f}-\mathbf{i})$ Corrected interferograms using the tropospheric total delay maps in the first row, and $(\mathbf{j}-\mathbf{m})$ Phase-elevation plots of the uncorrected interferogram (black dots) versus the total delay map (colored dots). The geographic extent and colorbar scale for all the interferograms and delay maps are the same, as indicated by the original uncorrected interferogram. The colorbar scale for the GACOS resultsis indicated on the GACOS total delay map. The black triangles in the interferograms and maps indicate the location of Telica volcano in the CSK scene, which is masked out for the phase-elevation plots.

Approximately 34 uncorrected interferograms have an $R^{2} \geq 0.1$, and 165 interferograms with $R^{2}$ $<0.1$, suggesting that turbulence is playing a dominate role in the tropospheric phase delays within the interferograms. Comparing the phase-elevation plots for all 199 interferograms visually, none of the linear phase delay maps capture the same range in LOS phase as the uncorrected interferograms; however, they demonstrate a similar phase-elevation trend in $\sim 67 \%$ of the interferograms. For the trends in the GWM phase-elevation plots for all 199 interferograms, we noted the ranges in elevation for which the GWM phase-elevation plots diverged from that of the uncorrected phase-elevation plots. An example of this concept can be seen in Figure $2 \mathrm{~m}$, where the GACOS phase-elevation plot diverges from the uncorrected dataset around 350-400 m elevation. Divergences were observed for $37 \%, 55 \%$ and $90 \%$ of the phase-elevation plots for ERA5, NARR and GACOS respectively. The majority of the divergences for the ERA5 and NARR plots appeared to fall between $1100-1500$ m elevation. While $20 \%$ of the diverging GACOS phase-elevation plots also occurred between 1200-1500 m elevation, the majority of the divergences were observed between 500-1000 m. Overall, all of the GWM phase-elevation plots have good agreement (same trend and range in LOS phase) with each other and the uncorrected interferograms in about $18 \%$ of the interferograms, and all GWMs had poor agreement (opposite trend and/or poor range in LOS phase) in about 7\% of the interferograms (Figure S8a). About $30 \%$ of the interferograms show a good correlation between ERA5 and NARR total delay maps with each other and the uncorrected interferograms. ERA5 has the highest overall correlation with the uncorrected interferograms compared to the other GWMs in $15 \%$ of the interferograms, followed by NARR only and GACOS only in $6 \%$ and $4 \%$ of the interferograms respectively.

\section{Variance and Variance Reduction}

In general, the average variance of the corrected interferograms did not appear to vary much from that of the uncorrected interferograms (Table 3). The linear correction has the lowest average 
variance as well as the lowest range in variance for the full scene, while the ERA5 and NARR corrected interferograms share similar results to that of the uncorrected interferograms. GACOS corrected interferograms have the highest average variance as well as the highest range in variance.
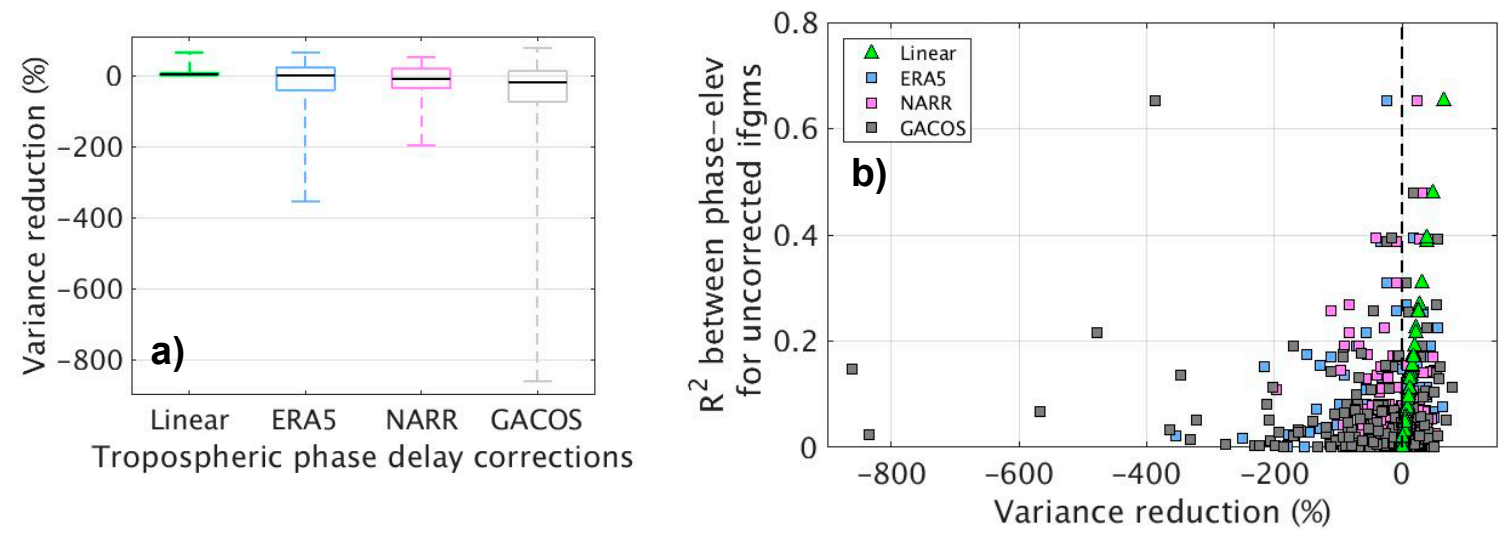

Figure 3. Variance reduction and $\mathrm{R}^{2}$ results for the 199 Telica descending CSK uncorrected and corrected interferograms. (a) Variance reduction box plots, and (b) $R^{2}$ derived from uncorrected interferograms phase-elevation plots versus the associated variance reduction results shown in (a).

Table 3. Statistical analyses of uncorrected and corrected interferograms for both Telica and Masaya CSK datasets. For each volcano, the average variance $\left(\right.$ in $\mathrm{cm}^{2}$ ) and variance reduction (\%) for all interferograms are indicated in bold. The values given in brackets indicate the minimum and maximum range for the variance and variance reduction. The range in variance reduction values are also shown in Figure 3 and Figure 8.

\begin{tabular}{|c|c|c|c|c|}
\hline \multirow{2}{*}{ Correction Method } & \multicolumn{2}{|c|}{ Telica } & \multicolumn{2}{|c|}{ Masaya } \\
\hline & $\operatorname{Var}\left(\mathrm{cm}^{2}\right)$ & Var Red (\%) & $\operatorname{Var}\left(\mathrm{cm}^{2}\right)$ & Var Red (\%) \\
\hline Uncorrected & $\begin{array}{c}5.44 \\
(0.60,43.94)\end{array}$ & - & $\begin{array}{c}\mathbf{5 . 6 9} \\
(0.71,47.55)\end{array}$ & - \\
\hline Linear & $\begin{array}{c}5.23 \\
(0.55,43.51)\end{array}$ & $\begin{array}{c}5.97 \\
(-0.33,65.40)\end{array}$ & $\begin{array}{c}\mathbf{5 . 4 3} \\
(0.49,47.44)\end{array}$ & $\begin{array}{c}\mathbf{6 . 6 5} \\
(-3.21,42.47)\end{array}$ \\
\hline ERA5 & $\begin{array}{c}5.55 \\
(0.65,44.21)\end{array}$ & $\begin{array}{c}\mathbf{- 1 7 . 5 8} \\
(-353.73,64.19)\end{array}$ & $\begin{array}{c}\mathbf{6 . 3 6} \\
(4.46,64.40)\end{array}$ & $\begin{array}{c}\mathbf{- 2 0 . 9 4} \\
(-675.48,70.12)\end{array}$ \\
\hline NARR & $\begin{array}{c}\mathbf{5 . 5 4} \\
(0.79,46.32)\end{array}$ & $\begin{array}{c}\mathbf{- 1 1 . 6 3} \\
(-197.08,51.80)\end{array}$ & $\begin{array}{c}\mathbf{6 . 6 8} \\
(0.56,62.82)\end{array}$ & $\begin{array}{c}-24.56 \\
(-364.80,58.07)\end{array}$ \\
\hline GACOS & $\begin{array}{c}\mathbf{6 . 5 8} \\
(0.74,54.89)\end{array}$ & $\begin{array}{c}-53.61 \\
(-863.31,78.30)\end{array}$ & $\begin{array}{c}\mathbf{5 . 9 2} \\
(0.64,50.90)\end{array}$ & $\begin{array}{c}-20.37 \\
(-286.53,83.32)\end{array}$ \\
\hline
\end{tabular}

The variance reduction results indicate that the different tropospheric correction methods perform differently in terms of reducing the noise within the interferograms (Table 3, Figure 3a). From the average variance reduction results, only the linear correction reduces the variance within the interferograms, although only by around $6 \%$ on average. The GWM results on the other hand, all indicate moderate ( $\sim 12 \%$ for NARR) to very large increases in variance ( $\sim 54 \%$ for GACOS) after the GWM total delay maps are applied. Examining the variance reduction results for all interferograms (Figure 3a), the linear corrected interferograms demonstrate a reduction in variance for $97 \%$ of the interferograms, whereas the ERA5 corrected interferograms demonstrate a reduction in variance in about $49 \%$ of the interferograms. NARR corrected interferograms demonstrate a variance reduction in $43 \%$ of the interferogram dataset, while GACOS corrected interferograms demonstrate a variance reduction in only $33 \%$ of the interferograms. Of all the GWMs, NARR corrected interferograms have the lowest range in variance reduction results, with a maximum variance increase of $\sim 197 \%$ for a single interferogram, followed by ERA5 corrected interferograms with a maximum variance increase of $\sim 354 \%$ in a single interferogram. GACOS corrected interferograms demonstrate the largest range in 
variance reduction results, as well as the highest maximum variance increase of $\sim 863 \%$ for a single interferogram and highest maximum variance reduction of $\sim 78 \%$ for a single interferogram (Figure $3 a$ ).

Correcting for Stratified and Turbulent Components

As seen from the results thus far, CSK interferograms spanning Telica appear to have a combination of stratified and turbulent tropospheric phase delays. By plotting the coefficient of determination from the uncorrected interferogram phase-elevation plots against the variance reduction results after the different corrections have been applied, we can quantitatively assess the effectiveness of each correction method to account for stratified and/or turbulent tropospheric phase delays. The clearest correlation is observed for the linear correction method, where for increasing $\mathrm{R}^{2}$ values the linear method reduces the variance (Figure 3b). For the GWMs, correlation is less apparent. The majority of the GWM corrected interferograms ( $\sim 75 \%)$ are centered over the zero-variance reduction line and within the $100 \%$ variance increase/reduction bounds. The interferograms outside of these bounds are associated with ERA5 and GACOS corrected interferograms and $\mathrm{R}^{2}$ values less than 0.2 , with the exception of two GACOS corrected interferograms.

\subsubsection{Time-Series Analysis}

The time-series plot for the Telica dataset was focused on the TECF GPS location as it is located closest to the summit and falls within a permanently high coherence region on Telica's SE flank (Figure 4a). We chose a single coherent pixel that was closest to the location of TECF for the InSAR time-series plot. The reference region for the time-series analysis was selected in an all-year round coherent region to the SW of Telica as the average of a 2-by-2 pixel area (180-by-180 $\mathrm{m}^{2}$ area) (Figure 4a). We first focus on the corrected and uncorrected InSAR time-series results, followed by a comparison with the GPS data from the station TECF.

The general trend of all the InSAR time-series results are fairly scattered in terms of LOS displacement between December 2014 until the end of Phase I of volcanic activity, i.e., have varying ranges in LOS displacement (Figure 4b). After June 2015 until the end of December 2015, the time-series results for all the datasets have a tighter LOS displacement pattern with less scatter. Regardless of the differences in the LOS displacement magnitudes and spread, all of the datasets tend to follow a similar fluctuating pattern in LOS displacement. Computing the variance for each time-series, the ERA5 corrected time-series is the only time-series that demonstrates an overall decrease in variance, from $2.02 \mathrm{~cm}^{2}$ to $1.71 \mathrm{~cm}^{2}$. All remaining tropospheric correction methods increase the variance in the time-series: NARR corrected $\left(2.46 \mathrm{~cm}^{2}\right)$, linear corrected $\left(2.75 \mathrm{~cm}^{2}\right)$ and the largest scatter for GACOS corrected $\left(6.20 \mathrm{~cm}^{2}\right)$.

GPS data from TECF, converted into the CSK descending LOS, exhibits broad annual and semi-annual signals, ranging between -2 to $3 \mathrm{~cm}$ LOS displacement (Figure 5a). The uncorrected InSAR time-series has a fairly tight correlation with that of the GPS LOS time-series, except for several dates in 2015 (also indicated on Figure 5a): 9 February, 14 April, 24 May, 5 September, and 9 September. Comparing with the InSAR time-series results shown in Figure 4b, we observe that prior to June 2015, the InSAR tropospheric correction method time-series results have large ranges in LOS displacement across the GPS LOS displacements (Figure 5b). However, after June 2015 and leading up to Phase II of the 2015 activity, the linear and GWM corrected time-series datasets follow a tighter pattern during this period, i.e., smaller ranges in LOS displacement. 

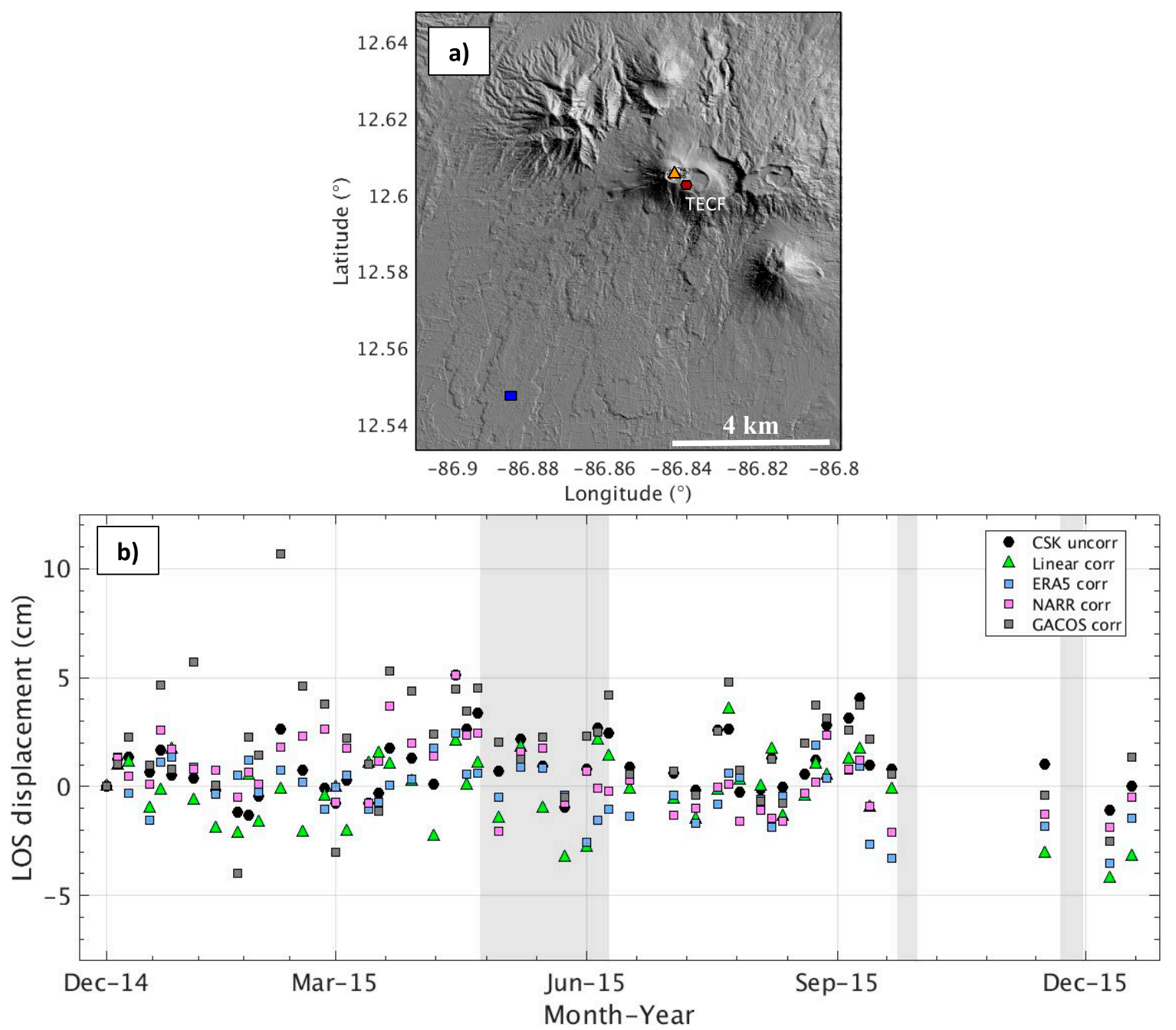

Figure 4. InSAR uncorrected and corrected time-series results for Telica CSK centered over GPS station TECF (199 interferograms made from 50 CSK acquisition dates). (a) Hillshade topography image showing the location of TECF GPS station (red hexagon), the reference region used in the time-series analysis (blue rectangle), and the summit of Telica volcano (orange triangle). (b) InSAR time-series results centered over GPS station TECF. The grey shaded regions in the time-series plots indicate the three phases of explosive activity as defined by Roman et al. [81]. Error bars were not computed for InSAR data as the time-series is plotted for a single pixel.

\subsection{Masaya Volcano}

\subsubsection{Background}

Masaya caldera is a basaltic volcano located $\sim 20 \mathrm{~km}$ SE of Managua City in central Nicaragua $(11.984 \mathrm{~N}, 86.161 \mathrm{~W})$ (Figure 6). The caldera consists of Masaya Lake in the SE corner, and the summit in the NW region consists of several nested pit craters: San Pedro, San Fernandino, Santiago and Nindiri, with a maximum elevation of $\sim 600 \mathrm{~m}$ [84]. Masaya exhibits a wide range of effusive and explosive activity, including lava flows, lava lakes, and major to minor phreatomagmatic to Plinian periods of activity [84-87]. The lava lakes are typically located within one of the nested pit craters located at the summit [88]. Since the formation of Santiago pit crater in 1858-1859, the majority of volcanic activity has been hosted within this pit crater $[84,85,89]$. The most recent period of unrest at Masaya started in December 2015, when a lava lake appeared within Santiago pit crater [84]. There were no visual indications prior to the lava lake appearance that there were changes occurring within the system, and 
the only seismometer in the caldera failed in September 2015 [90]. According to bulletins published by INETER, the last time a lava lake was fully present in the Santiago pit crater was in October 2006 [91]. There have been a number of different studies spanning the appearance of the lava lake in 2015 in order to further understand the subsurface processes occurring within the magma plumbing system. Independent geodetic observations using precision leveling [92,93] and InSAR [5] captured a region of uplift located $\sim 3 \mathrm{~km}$ north of the Santiago summit pit crater, with vertical uplift of $\sim 5.5 \mathrm{~cm}$ and $\sim 8 \mathrm{~cm}$ respectively. Gas geochemistry studies observed a peak in the $\mathrm{CO}_{2} / \mathrm{SO}_{2}$ ratio $\sim 2$ weeks prior to the lava lake appearance, and was interpreted as a pulse of gas-rich magma from depth into the magma plumbing system [94]. Observations of the $\mathrm{SO}_{2}$ flux spanning a 3-year period indicate that the appearance of the lava lake has increased the $\mathrm{SO}_{2}$ degassing flux to $>1500 \mathrm{t} / \mathrm{d}$ [95]. During the period of interest, only one GPS station within the caldera was operating and taking continuous measurements, beginning in November 2015.
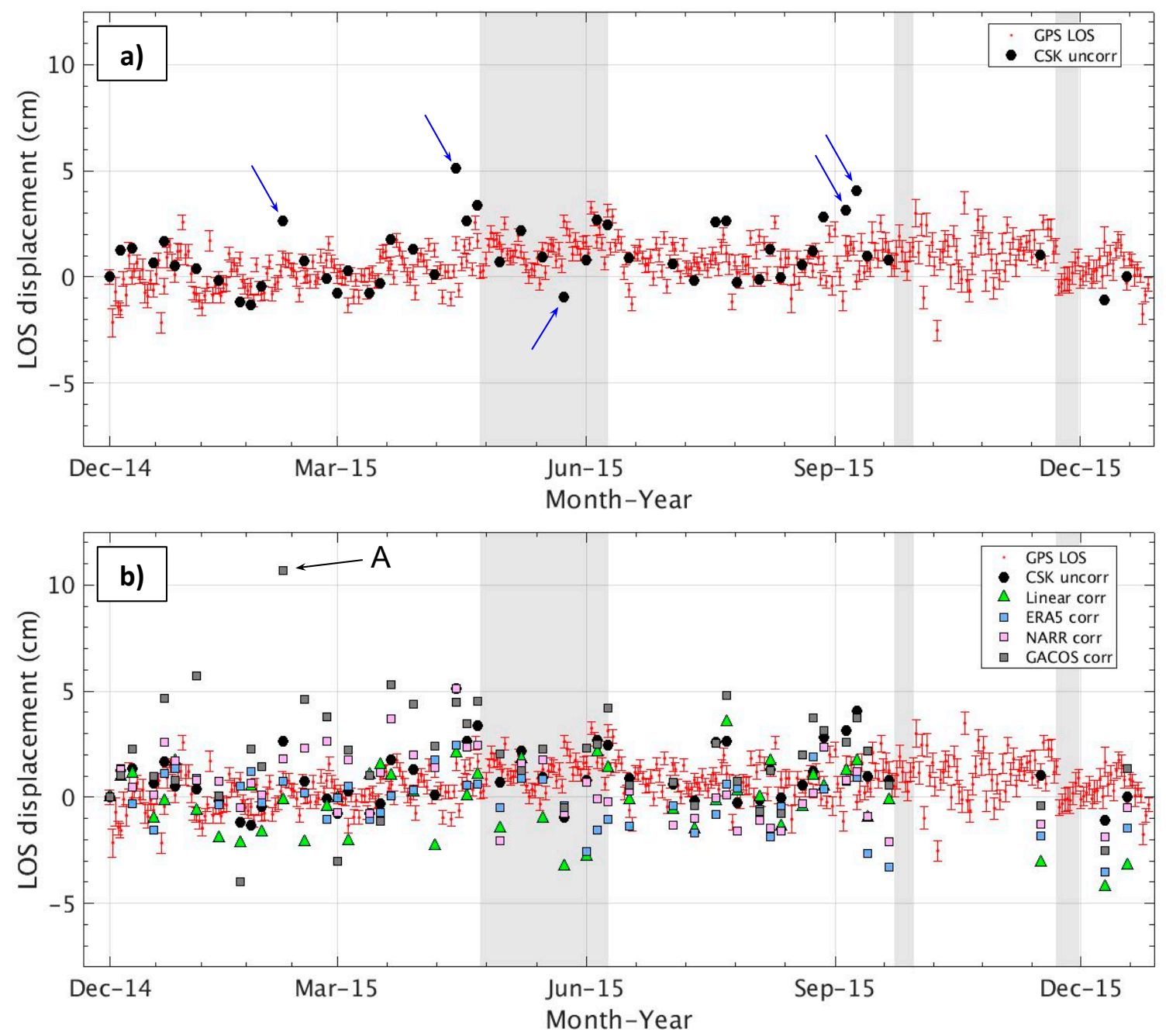

Figure 5. LOS displacement time-series plots of GPS station TECF against (a) InSAR uncorrected, and (b) InSAR uncorrected and corrected time-series at the same location (199 interferograms made from 50 CSK acquisition dates). The three components from the GPS data were converted into the LOS of CSK descending path over Telica volcano (red dots). The InSAR symbols are the same as those used in Figure 4 b. Error bars were not computed for InSAR data as the time-series is plotted for a single pixel. The grey shaded regions indicate the three phases of explosive activity observed in 2015 [81]. The blue arrows in (a) indicate visually identified outlier dates in the InSAR uncorrected time-series. The labelled GACOS time-series outlier in (b) as A is discussed further in Section 4.2. 


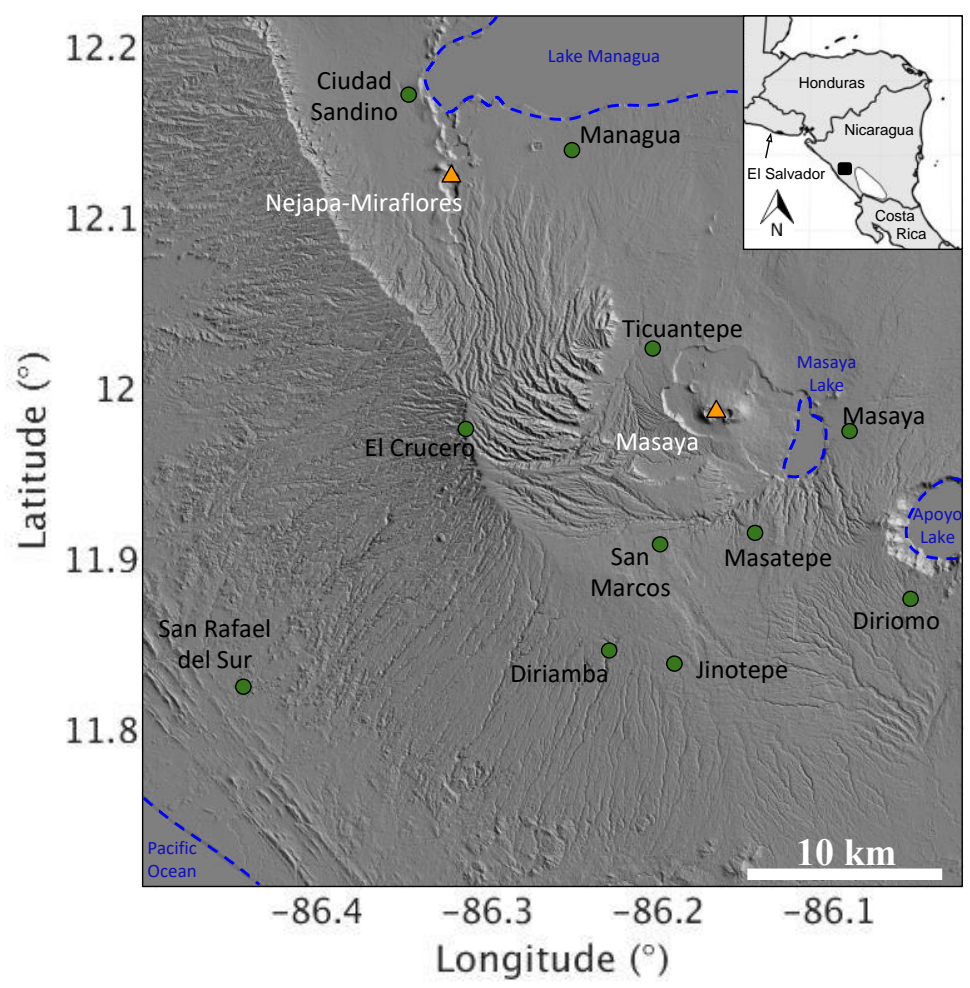

Figure 6. Hillshade topography image obtained using the TanDEM-X digital elevation model of CSK ascending scene covering Masaya caldera. Orange triangles indicate Holocene volcanoes [82] and nearby towns with populations greater than 10,000 are indicated with green circles [83]. Bodies of water are indicated in blue writing and dashed lines. Inset image indicates the location of the CSK scene in Nicaragua.

\subsubsection{Masaya InSAR Dataset}

We obtained 60 ascending CSK images spanning 10 August 2015 until 15 October 2016. Following the criteria tests for coherence and network connectivity criteria, 281 interferograms were created from the 60 acquisitions (Figure S2). These CSK scenes are dominated by broad regions of valleys and mountains, and thus a mixture of stratified and turbulent atmospheric phase delays is expected.

\subsubsection{Tropospheric Phase Delay Correction Results}

Below, we present the statistical assessment results from the application of the empirical and predictive tropospheric correction methods to the Masaya CSK interferograms. Masaya caldera was masked out prior to statistical analyses in order to remove any potential contributions from the deforming region within the caldera to the atmospheric noise estimates.

\section{Phase-Elevation Plots}

An example of the phase-elevation relationship for a single interferogram pair (20160617-20160711) from the Masaya ascending CSK dataset is shown in Figure 7. Both the linear correction and ERA5 total delay maps (Figure $7 \mathrm{~b}, \mathrm{c}$ ) and phase-elevation plots (Figure 7j,k) show minimal LOS phase during this time period. The NARR and GACOS phase-elevation plots (Figure 7l,m) indicate that they are capturing a similar phase-elevation relationship to that of the uncorrected interferogram. The slight discrepancy between the LOS magnitudes for the uncorrected, and NARR and GACOS phase-elevation plots is likely a function of the area used to re-reference the corrected interferograms. The total delay maps for NARR and GACOS (Figure 7d,e), however, suggest that the phase delay patterns are not the same as that seen in the uncorrected interferogram (Figure 7a). 

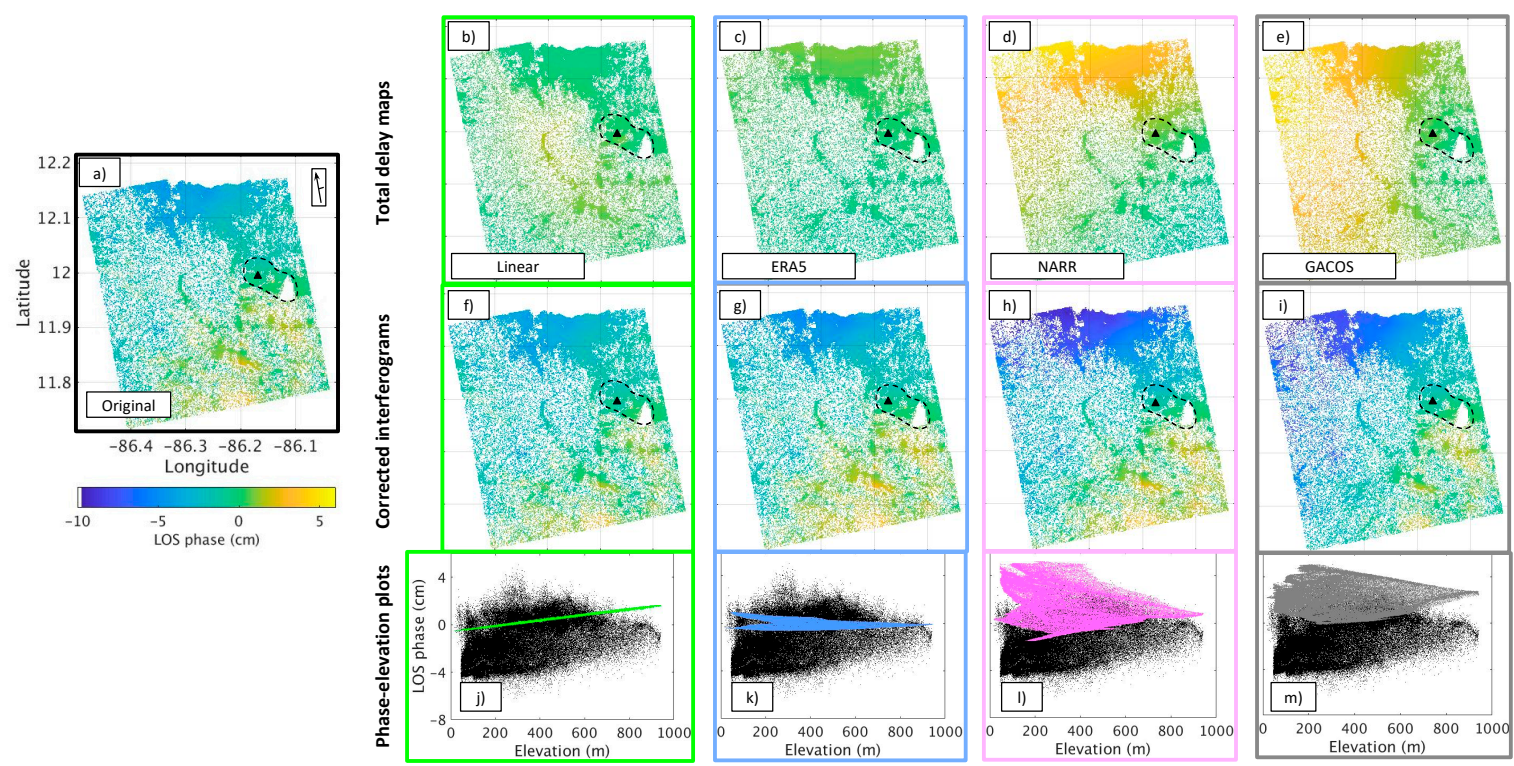

Figure 7. Comparison of the different tropospheric phase delay correction methods for Masaya unwrapped interferogram 20160617-20160711. (a) Uncorrected interferogram, (b-e) Total tropospheric delay map for each correction method, $(\mathbf{f}-\mathbf{i})$ Corrected interferograms using the tropospheric delay maps from the first row, and $(\mathbf{j}-\mathbf{m})$ Phase-elevation plots of the uncorrected interferogram (black dots) versus the total delay map (colored dots). The geographic extent and colorbar scale for all the interferograms and delay maps are the same, as indicated by the original uncorrected interferogram. The black triangles in the interferograms and maps indicate the location of the summit of Masaya in the CSK scene, and the outline of Masaya caldera.

Approximately 80 uncorrected interferograms phase-elevation plots have $R^{2} \geq 0.1$, and 201 with $\mathrm{R}^{2}<0.1$ (Figure 8b). This suggests that the majority of the CSK scenes used contain turbulent phase delays. Unlike the Telica phase-elevation plots, the Masaya scenes are slightly more complicated in terms of the spread in LOS phase. In some cases, the uncorrected phase-elevation plots appear to have two lobes of LOS phase between 0-300 m elevation (Figure S5). Examination of the associated unwrapped uncorrected interferograms to account for these lobes suggests an apparent ramp in the data, which was only captured in $43 \%, 19 \%$ and $35 \%$ of the ERA5, NARR and GACOS phase-elevation plots, respectively. Visual examination of the phase-elevation plots for all 281 corrected interferograms suggest that the GWMs all have good agreement with the uncorrected interferograms for about $27 \%$ of the interferograms, and about $17 \%$ where all of the GWMs have poor agreement (Figure S8). The linear phase-elevation plots have poor agreement in terms of range in LOS phase compared to the uncorrected interferograms; however, they capture a similar phase-elevation trend in $\sim 70 \%$ of the interferograms. Approximately $7 \%$ of the phase-elevation plots demonstrate a good agreement of ERA5 and NARR total delay maps with the uncorrected interferograms, and 13\% for ERA5 and GACOS total delay maps. GACOS total delay maps appear to have the highest correlation with the uncorrected interferograms compared to ERA5 and NARR in about $16 \%$ of the interferograms (Figure S8).

\section{Variance and Variance Reduction}

The average variance of the full scenes demonstrates that only the linear corrected interferograms have an average variance lower than that of the uncorrected interferograms (Table 3). All three GWMs have average variances higher than that of the uncorrected interferograms, with the highest observed corresponding to the NARR corrected interferograms $\left(6.68 \mathrm{~cm}^{2}\right)$. 

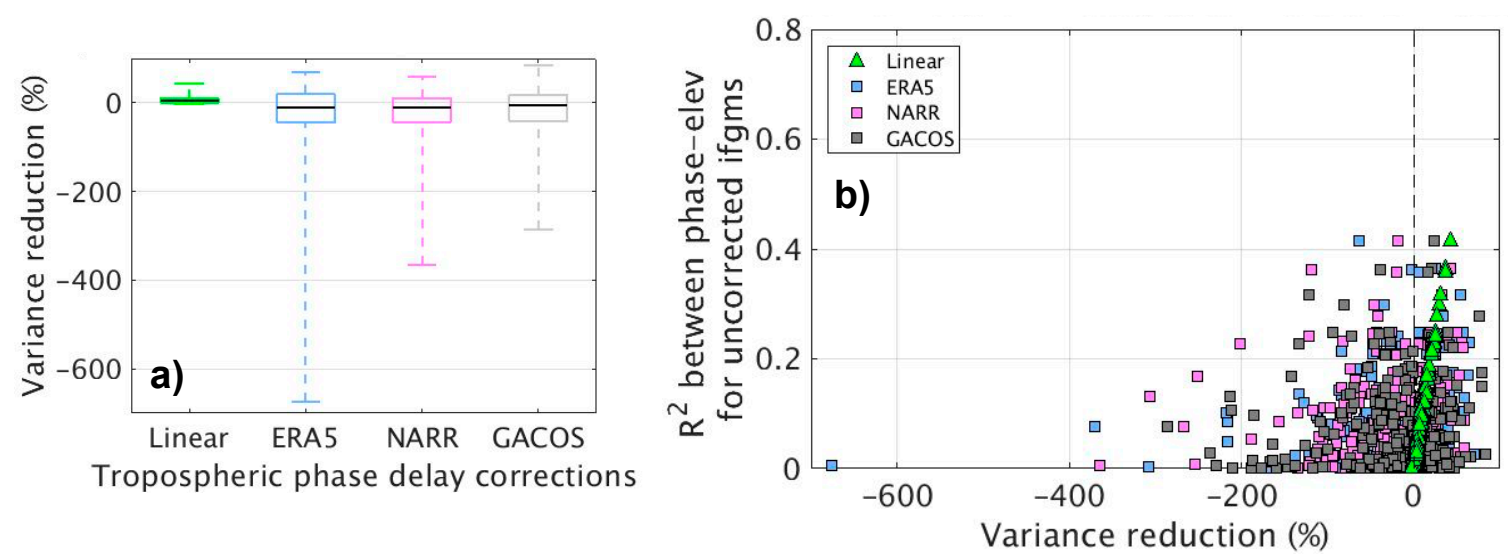

Figure 8. Variance reduction and $\mathrm{R}^{2}$ results for the 281 Masaya ascending CSK uncorrected and corrected interferograms. (a) Variance reduction box plots, and (b) $\mathrm{R}^{2}$ derived from uncorrected interferograms phase-elevation plots versus the associated variance reduction results shown in (a).

The variance reduction results for Masaya full scenes suggest that the linear correction reduces the variance in $\sim 85 \%$ of all interferograms, with an average variance reduction of $\sim 7 \%$ (Table 3, Figure 8 a). ERA 5 and GACOS reduce the variance in about $43 \%$ of the interferograms, while NARR corrected interferograms only reduced the variance in about $38 \%$ of the interferograms. All three GWMs performed similarly in terms of average variance reduction, with ERA5 and GACOS demonstrating a variance increase between $20-21 \%$, and NARR increasing the variance by $25 \%$ on average. While NARR has a maximum variance increase of $\sim 365 \%$ for a single interferogram, ERA 5 demonstrates the overall maximum variance increase of $\sim 675 \%$.

Correcting for Stratified and Turbulent Components

As seen from the results shown thus far, the CSK scenes over Masaya contain a mixture of turbulent and stratified phase delay components. We observe that in general, the phase-elevation correlation for the uncorrected interferograms is fairly low, where the majority of the relations are $\mathrm{R}^{2}<$ 0.1 (Figure $8 \mathrm{~b}$ ). Plotting these results against the variance reduction after the different tropospheric corrections have been applied, the linear correction shows a clear correlation of increasing variance reduction with increasing $\mathrm{R}^{2}$ values. For the GWM corrected interferograms, there does not appear to be as clear of a trend.

\subsubsection{Time-Series Analysis}

Two regions were selected within the Masaya dataset for time-series plotting: the first is located according to the preferred model for the center of displacement as determined by previous InSAR modeling [5], and the second is located at the site of GPS station MAVC (Figure 9a). MAVC is the closest GPS station to the observed displacement within Masaya caldera and is located at the Visitor's Center within Masaya caldera. For both InSAR time-series regions, the average of a 2-by-2-pixel area (180-by-180 $\mathrm{m}^{2}$ area) was selected in Masaya town as the reference region (Figure 9a). For the preferred model time-series location, we averaged an area of 5-by-5 pixels (450-by-450 $\left.\mathrm{m}^{2}\right)$ centered over the preferred model location. A single coherent pixel closest to the location of MAVC GPS station was selected for the second time-series location. 

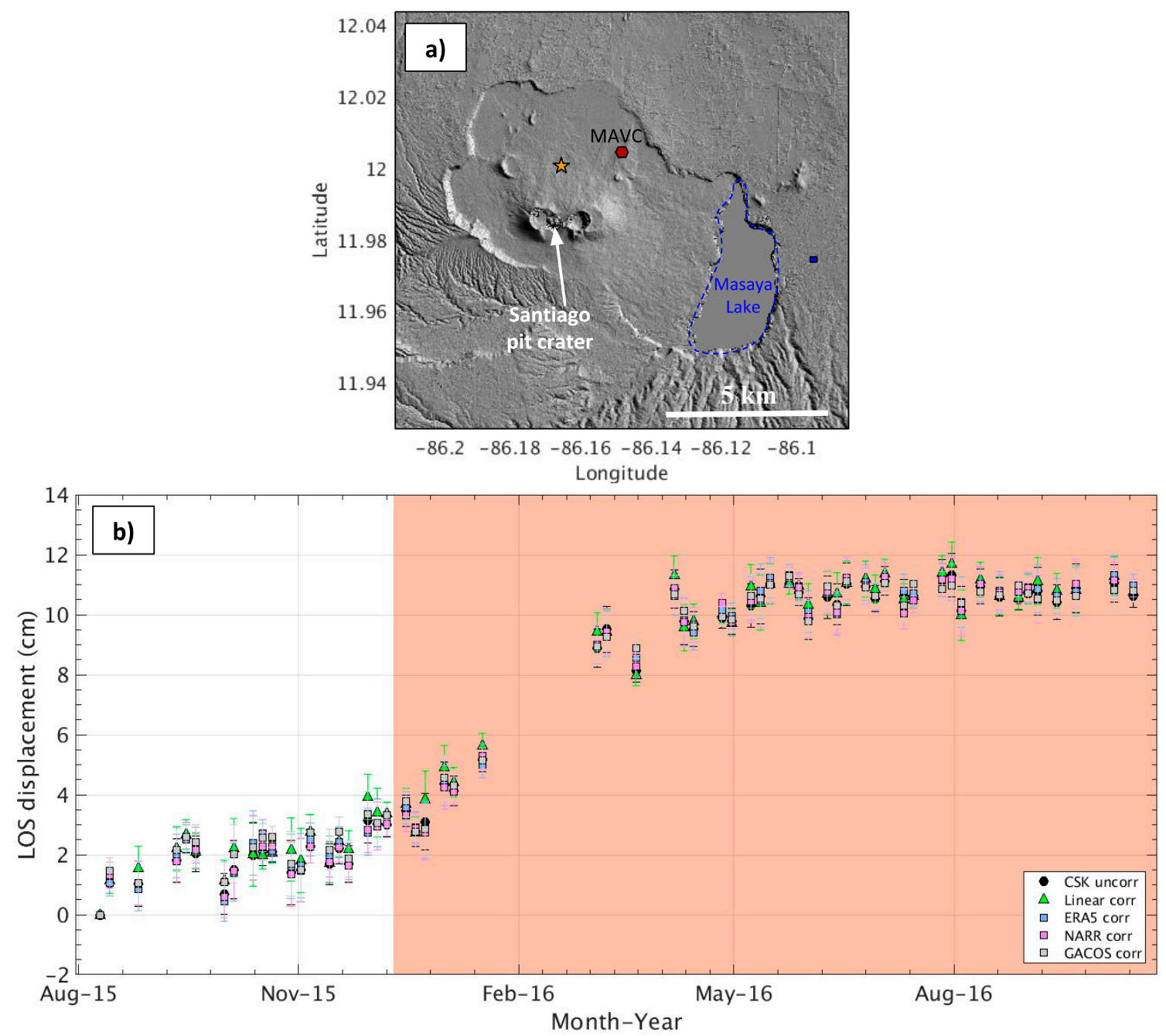

Figure 9. InSAR time-series results for Masaya CSK (281 interferograms made from 60 CSK acquisition dates). (a) Hillshade topography image showing the area selected for the time-series centered over the preferred model spherical source location from Stephens \& Wauthier [5] (orange star), the reference region for time-series analysis within Masaya town (blue rectangle), and the location of GPS station MAVC (red hexagon). (b) Time-series plot for the uncorrected and corrected InSAR datasets centered over the preferred model source location. The orange shaded region in the time-series plot indicates the presence of the lava lake in Santiago pit crater. Plotted error bars represent the standard deviation of the selected time-series region.

For the preferred model center of displacement time-series plot, we observe a distinctive LOS displacement pattern in the uncorrected InSAR time-series (Figure 9b). The LOS displacement increases prior to and during the appearance of the lava lake in the Santiago pit crater, reaching a maximum of $\sim 11.5 \mathrm{~cm}$ positive LOS displacement. Visually, all four InSAR corrected time-series results display very little variability in LOS displacement between each other and with the uncorrected dataset, reaching the same magnitude in LOS displacement.

The MAVC GPS data (spanning November 2015-November 2016) converted into the CSK ascending LOS exhibit a similar pattern to that in Figure $9 \mathrm{~b}$ of increasing positive LOS displacement associated with the appearance of the lava lake (Figure 10a). From November 2015 until late January 2016, the GPS and uncorrected InSAR time-series results both capture a very distinct increase and decrease LOS displacement pattern. However, after the temporal gap in the InSAR time-series, the uncorrected InSAR time-series and GPS LOS time-series do not appear to be capturing the same magnitude of LOS displacement. In May 2016, the GPS increases until a peak in LOS displacement, 
which is not matched by the uncorrected InSAR time-series dataset. In contrast, the uncorrected time-series appears to be reaching a plateau in LOS displacement similar to Figure 9b, but at a lower magnitude in LOS displacement of $\sim 4 \mathrm{~cm}$. Comparing with the corrected InSAR time-series results, we again observe the distinct increase and decrease pattern in LOS displacement with the GPS LOS time-series dataset between November 2015 and January 2016 (Figure 10b). After the temporal gap in the InSAR dataset, all four corrected InSAR time-series follow the uncorrected InSAR time-series pattern, reaching a positive LOS displacement plateau of $\sim 4 \mathrm{~cm}$.
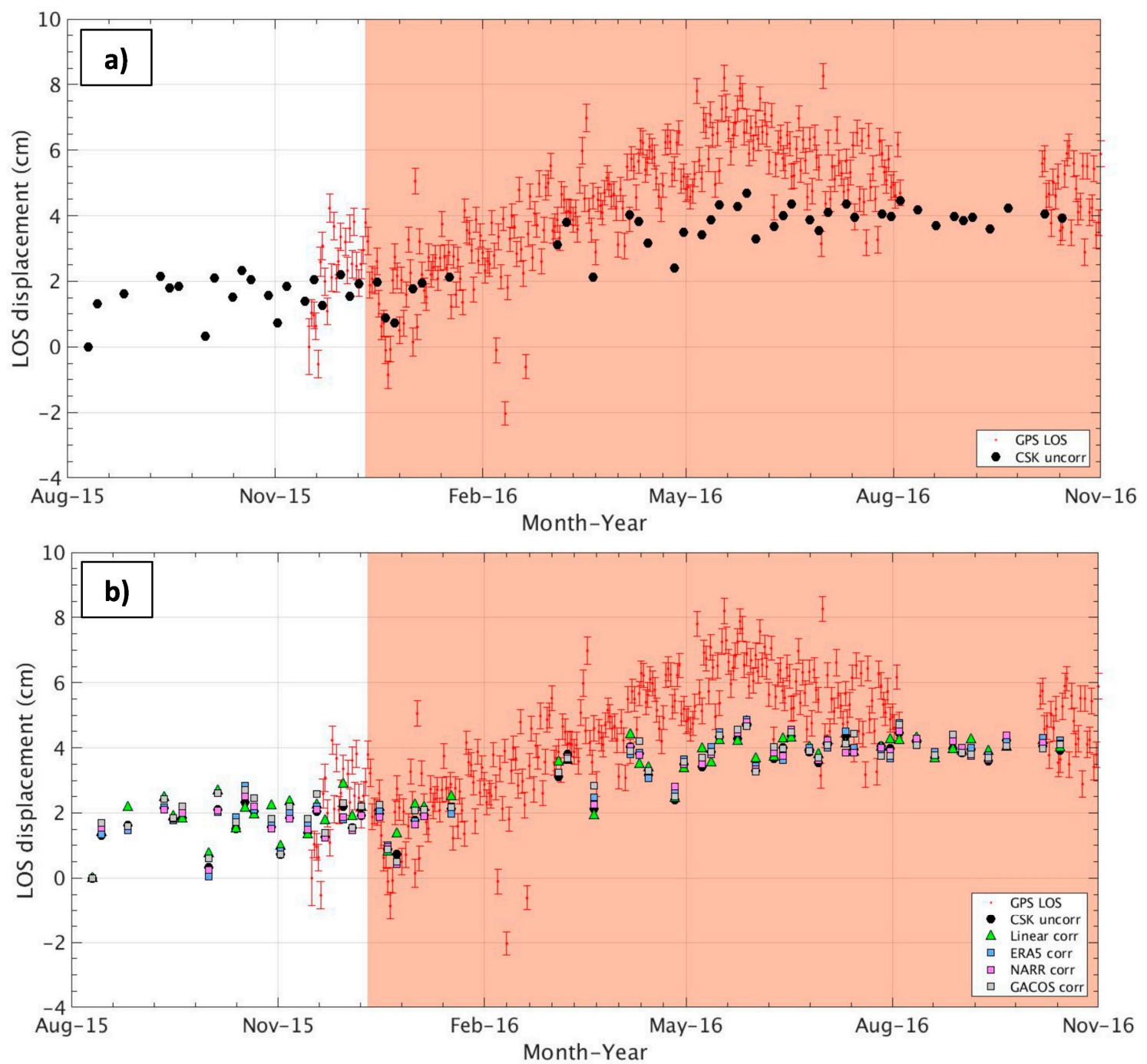

Figure 10. LOS displacement time-series plots of GPS station MAVC against (a) InSAR uncorrected, and (b) InSAR uncorrected and corrected time-series at the same location (281 interferograms made from 60 CSK acquisition dates). The three components from the GPS data were converted into the LOS of CSK ascending path over Masaya caldera (red dots). The InSAR symbols are the same as those used in Figure 11b. Error bars were not computed for InSAR data as the time-series is plotted for a single pixel. The orange shaded region in the time-series plots indicates the presence of the lava lake in Santiago pit crater. 
a)

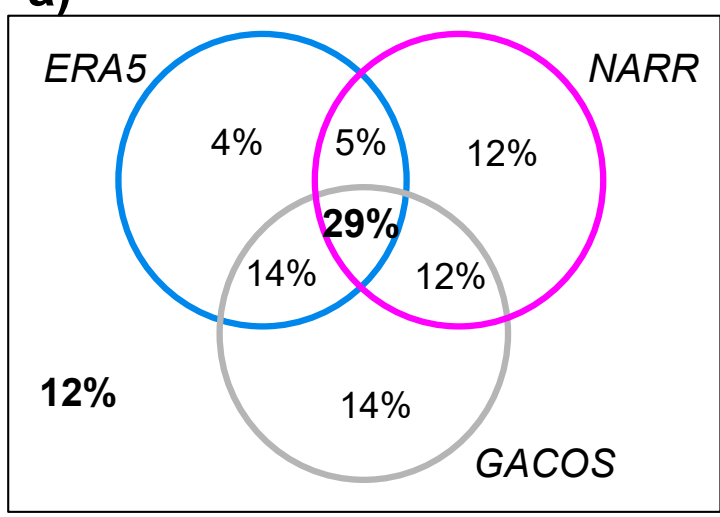

b)

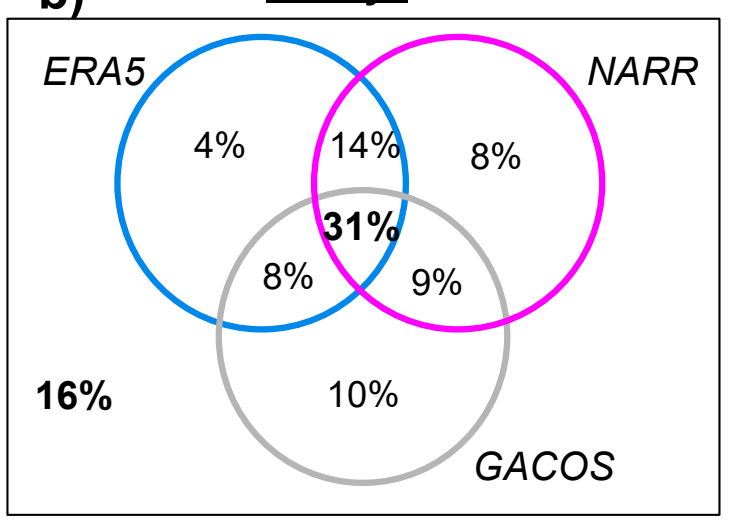

Figure 11. Venn diagrams displaying the increase in variance results for the GWM datasets only at Telica (a) and Masaya (b). Within the circles, each number represents the percentage of interferograms for which the GWM increased the variance in the corrected interferogram. The numbers outside the circles represent the percentage of interferograms for which all GWMs demonstrated a reduction in the variance for a single interferogram. The converse of these Venn diagrams (variance reduction) are given in Figure S9.

\section{Discussion}

In this section we first discuss and compare the statistical assessments and time-series results for both Telica and Masaya, and then discuss the overall performance of the different tropospheric phase delay methods in context with other studies.

\subsection{Statistical Assessments Results}

From the phase-elevation plots, the linear total delay maps do not capture the spread in LOS phase of the uncorrected interferograms at both Telica and Masaya. The general slope of the linear total delay maps matches well with that of the uncorrected interferograms, which is expected since the linear method estimates the stratified delay directly from the unwrapped interferograms. However, the linear total delay maps only reduce the variance by an average of $\sim 6-7 \%$, and in approximately $75 \%$ of the linearly corrected interferograms, the variance is only improved by $7-10 \%$ or less at both Telica and Masaya (Figures 3 and 8). The variance reduction does not drop significantly below zero (i.e., $~ 3 \%$ maximum variance increase at Masaya) as the linear empirical approach only removes correlated signal from the associated interferograms (Figures 3 and 8) [54]. Visually, none of the phase-elevation plots seem to indicate that one GWM outperforms another at both locations, with ERA5 capturing the trend and spread in LOS phase best at Telica in $~ 76 \%$ of the interferograms, and GACOS at Masaya in $~ 65 \%$ of the interferograms (Figure S8). At Telica, NARR outperforms GACOS in $\sim 61 \%$ of the interferograms versus $\sim 37 \%$, and ERA5 outperforms NARR in $53 \%$ of the interferograms versus $46 \%$ at Masaya. The observed two lobes of LOS phase at lower elevations over Masaya could potentially be interpreted as an orbital ramp. However, in some cases the GWMs were able to capture the two lobe LOS distribution (for example, Figure S5), suggesting that perhaps long-wavelength tropospheric features are more prevalent in the Masaya region compared to Telica. It is possible that this is a function of the broad topography of the Las Sierras shield to the west of Masaya caldera (Figure S3). It is also probable that the long wavelength feature is due to ionospheric effects, although it is less likely for X-band datasets.

Comparison of the variance reduction results for only the GWM corrected interferograms at Telica and Masaya are shown in Figure 11, where the numbers inside the circles indicate the percentage of interferograms for which variance increase is observed, i.e., noise is being added to the interferograms. All three GWMs increased the variance after the total phase delay maps were applied for a single interferogram in approximately $29 \%$ and $31 \%$ of the interferograms at Telica and Masaya respectively (Figure $11 \mathrm{a}, \mathrm{b}$ ). In contrast, only $12 \%$ and $16 \%$ of the interferograms demonstrated variance reduction 
in a single interferogram by all three GWMs. ERA5 appears to increase the variance the least, in approximately $52 \%$ and $57 \%$ of the interferograms at Telica and Masaya respectively. NARR and GACOS appear to switch performance at Telica and Masaya, with GACOS increasing the variance the most at Telica for approximately $69 \%$ of the interferograms, and NARR increasing the variance the most at Masaya for approximately $62 \%$ of the interferograms.

Turbulent atmospheric phase delays were visually identified in at least $56 \%$ of the uncorrected interferograms at Telica and 59\% at Masaya. From the $\mathrm{R}^{2}$ values, turbulent phase delays appear to be the dominant atmospheric features within the CSK scenes at both case study regions. From the semivariogram analyses (Figure S7), we observe that at $\sim 10 \mathrm{~km}$ lag distance the average variance ranges between $1.5-1.75 \mathrm{~cm}$ for both case study sites. Our results are double that observed in theoretical estimates of atmospheric noise over the Mojave desert in California, in which $\sim 0.8 \mathrm{~cm}$ variance was observed at $10 \mathrm{~km}$ lag distance [96]. Besides the fact that the two case study volcanoes are located in a tropical region with highly spatiotemporal variability in water vapor concentrations, this degree of turbulent noise versus stratified noise is expected, particularly because the full CSK scenes at Telica consists of mainly topographic lows and low gradient changes in elevation at Masaya (Figure 12c,d). In conjunction with the observation that Telica is located near the boundary between a two different tropical climate regions, the local acquisition time of the CSK datasets are also important to keep in mind (17:30 over Telica and 05:30 over Masaya). Acquisitions in the early evening are expected to contain more turbulent phase delays compared to early morning acquisitions due to solar heating of the atmosphere [54], which could potentially explain the difficulty that the tropospheric corrections had in capturing tropospheric phase delays at Telica.

\subsection{Time-Series Results (InSAR and GPS)}

The results from the statistical assessments provide more context for the InSAR time-series results at Telica and Masaya. At Telica, the scatter in the datasets is more clearly described by the variance of each time-series, with ERA5 reducing the variance the most (Figure $4 \mathrm{~b}$ ). It is important to note however that as the time-series for Telica is calculated for a single pixel on the SE flank of Telica volcano (860 $\mathrm{m}$ above sea level), the variation in LOS phase for a single pixel compared to an average of several pixels can vary greatly between subsequent interferogram pairs. The GACOS corrected time-series has the greatest scatter, and for the acquisition dates in which the zenith total delay maps do not capture the tropospheric phase delay accurately, noise is introduced into the corrected interferograms and is then reflected in the time-series results. For example, the GACOS time-series point on the 9 February 2015 (indicated on Figure 5b) is associated with eight interferograms, all of which exhibit variance increase of between $91 \%$ to $861 \%$.

On the other hand, the Masaya time-series results over the center of the 2015-2016 deforming region, as determined by the spherical preferred model, suggest that all three GWMs and the linear correction perform equally but do not significantly change the time-series results compared to the uncorrected InSAR time-series (Figure 9b). The minimal difference between the corrected and uncorrected time-series results is not surprising as the time-series location is at an elevation of approximately $320 \mathrm{~m}$ above sea level and in a region with a very low-angle slope towards Masaya's summit. Visual examination of individual uncorrected interferograms showed potential large-scale $(>10 \mathrm{~km})$ tropospheric phase delays in the CSK scenes; however, the displacement center observed within the caldera did not appear to be distorted by them. 

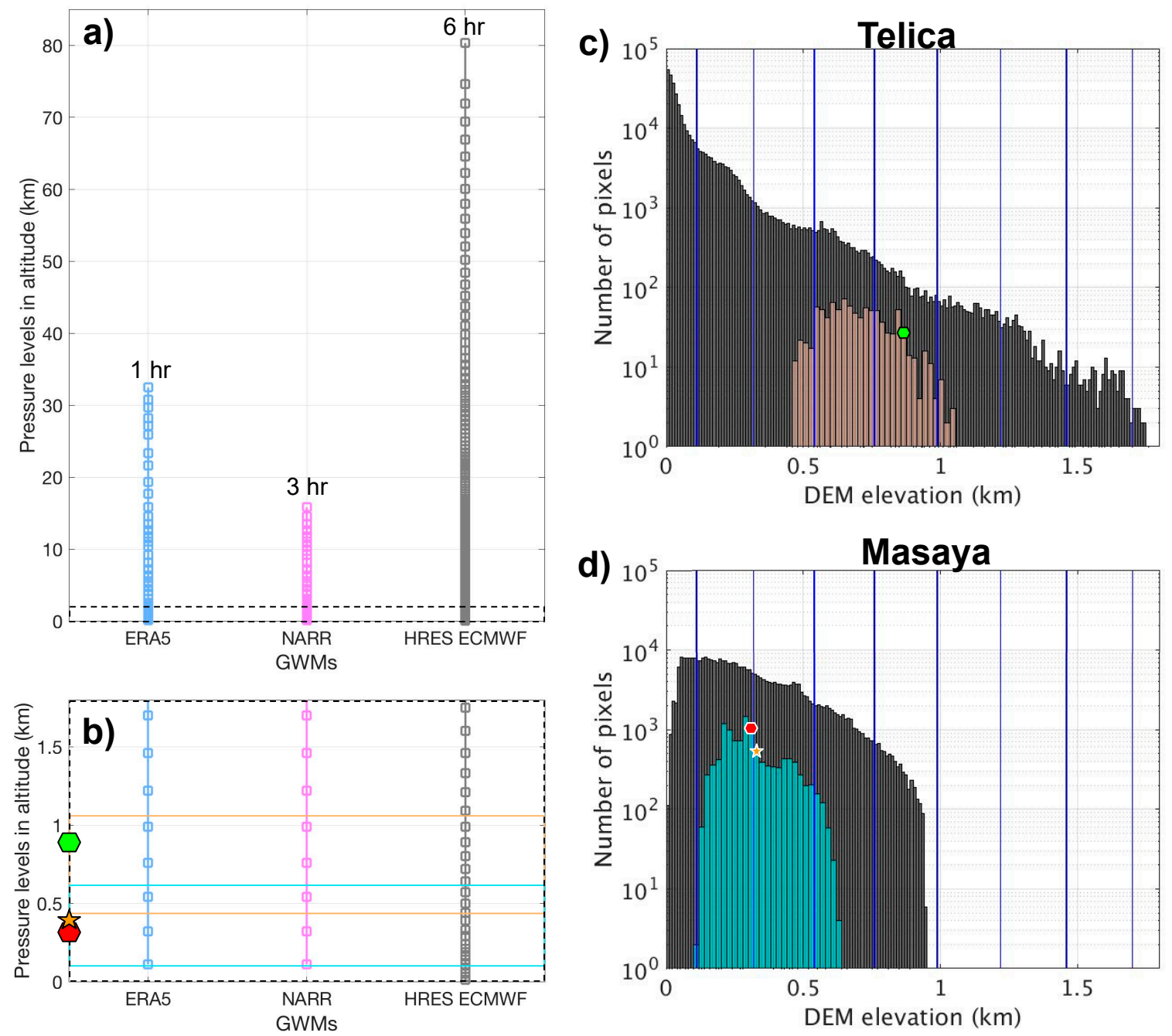

Figure 12. Vertical pressure levels resolution of GWMs in relation to elevation within the CSK scenes over both Telica and Masaya. (a) GWMs vertical pressure levels in kilometers altitude and associated temporal resolutions, the black dashed box indicates the zoomed in area in panel (b), (b) zoomed area of panel (a) that encompasses the maximum elevation of both CSK scenes, with the shaded regions indicating the elevation range specifically over Telica (orange) and Masaya (blue). The symbols indicate the elevation of GPS station TECF (green hexagon), MAVC station (red hexagon), and the preferred model center of displacement at Masaya (orange star). (c) Histogram plot of the range of pixel elevations within the Telica CSK full scene (black) and scene cropped to Telica edifice (orange), with the elevation of TECF station indicated (green hexagon). (d) Histogram plot of the range of pixel elevations within the Masaya CSK full scene (black) and scene cropped to Masaya caldera (blue), with the elevation of MAVC station (green hexagon) and preferred model center of displacement (orange star) indicated. The blue vertical lines in the histogram plots indicate the ERA5 and NARR coinciding vertical pressure levels as seen in panel (b).

\subsubsection{Telica GPS Results}

Despite the poor temporal sampling of the CSK dataset, overall the uncorrected InSAR time-series appears to capture the general trend of the GPS LOS time-series well (Figure 5). The outlier dates indicated in Figure 5 a may potentially be related to strong tropospheric artifacts present in interferograms associated with these dates. As the corrected InSAR time-series results do not appear to follow the same trend and LOS magnitude as that of the GPS results and also result in LOS displacement greater than that of the uncorrected InSAR time-series, we conclude that the correction 
methods applied appear to be overcorrecting for tropospheric phase delays within this region and are adding noise to the interferograms.

A recent study of the 2015 period of volcanic activity at Telica found that there was very subtle co-eruptive displacement during Phases II and III between TECF and two other GPS stations [81]. This signal was observed through baseline analysis between TECF and two other stations, one $500 \mathrm{~m}$ from the active crater and one $15 \mathrm{~km}$ from the active crater. These co-eruptive displacements are not evident in the InSAR time-series data, particularly because the InSAR temporal sampling between Phase II and III is poor. Following the temporal gap in the InSAR data (between dates 21 September-16 November 2015), the InSAR LOS displacements do not correlate as tightly with that of the GPS, however this is probably due to the poor network connectivity of interferograms associated with these dates (see Figure S1).

\subsubsection{Masaya GPS Results}

The magnitude of the LOS displacement for all of the InSAR time-series datasets at the MAVC GPS station location is consistent with what would be expected for a region on the outer edges of the deforming region associated with the lava lake within the Masaya caldera (December 2015 onwards) (Figure 10). The discrepancy between the GPS and all InSAR time-series datasets from April 2016 onwards may again be the result of poor temporal sampling in the InSAR data. In particular, the gap in the InSAR data between late January to March 2016 may have influenced the estimates for LOS displacement during the SBAS time-series analysis. Potential unwrapping errors in interferograms associated with dates from March 2016 onwards may be playing a role, however unwrapping errors were not observed within the vicinity of the center of deformation nor GPS station MAVC. As with the time-series results over the preferred deformation center in Figure 9b, the corrected InSAR time-series results at MAVC location do not appear to differ from the uncorrected InSAR results (Figure 10b). Again, this result is not surprising as the time-series location is at $\sim 300 \mathrm{~m}$ elevation on a shallow gradient slope within the caldera, and visual assessment of the interferograms did not indicate distortion of the deformation pattern within this region.

\subsection{Comparison of Tropospheric Phase Delay Corrections}

Following on from the discussion in the previous sections, we observe that the applicability of the compared tropospheric phase delay correction methods is highly case-dependent $[31,33,34]$. In this section we place our results and discussion in context with other InSAR studies involving tropospheric correction methods, as well as discuss the potential limitations of the different correction methods to capture the tropospheric noise within the interferograms.

According to previous studies, predictive correction methods are not able to capture turbulent tropospheric phase delays resulting from rapid changes in the lower troposphere due to the temporal and spatial resolution of GWMs [29,32-34,45-47], lack of input data and type of reanalysis procedure used in the data assimilation technique for each GWM [21,31,40]. A more recent study noted that none of the currently available correction methods are able to remove tropospheric effects with spatial extents smaller than $\sim 75 \mathrm{~km}$ [29]. Empirical corrections are focused on removing stratified tropospheric delays, and are thus not able to systematically capture the spatiotemporally random turbulent tropospheric delays $[25,27,29,97]$, which is confirmed in our study (Sections 3.1.3 and 3.2.3). Other studies incorporating a higher percentage of broad phase-elevation gradient regions have shown that the empirical method was more effective [47]. From the $\mathrm{R}^{2}$ values and range in elevation (Figure $3 \mathrm{~b}$, Figure 12c and Figure S3), the Telica region contains fairly localized topographic highs, and thus stratified tropospheric phase delay are only captured over a small percentage of our interferograms. While the Masaya region contains more broad phase-elevation gradients (Figure 12d and Figure S3), the linear correction only slightly outperformed at Masaya compared to Telica (Table 3).

Figure 12 demonstrates the vertical pressure level resolution of the GWMs at each grid node and focuses on the range in elevation corresponding to Telica and Masaya's CSK scenes. The initial 
expectation for the GWMs was that the higher the spatial resolution, both vertically and horizontally, the better the estimates of tropospheric phase delay would be. While HRES ECMWF has a much higher horizontal spatial and vertical resolution compared to ERA5 and NARR (Figure 12a,b and Figure S3), it fails to reliably capture turbulent phase delays within the troposphere, resulting in the introduction of noise into the interferograms and consequently into the time-series results at Telica. Besides the spatial resolutions, four additional main differences exist between the GWMs used in this study: (1) the data assimilation models used to create the forecast models (i.e., model physics and assumptions), (2) information on the observational data (i.e., the input data to the data assimilation models), (3) the temporal resolution of the GWMs, and (4) the method and assumptions used to interpolate and create the total delay maps from the raw GWM datasets. All of these factors can influence the ability of each GWM to accurately estimate the atmospheric parameters within these two case study regions. Unfortunately, there is little-to-no information regarding the datasets used in the data assimilation algorithms, thus increasing the difficulty in determining the accuracy of the forecasting datasets. While the spatial resolution of HRES ECMWF may still be insufficient to capture tropospheric noise in regions with rapidly varying topography, such as at Telica, the temporal resolution of the dataset may be playing a greater role in this study. As turbulent tropospheric phase delays can vary over timescales of less than $1 \mathrm{~h}$ [12], lower temporal sampling of the GWM data assimilation procedures can result in incorrect estimates of the atmospheric parameters at the time of the SAR acquisitions [40]. The fact that the observed atmospheric noise is almost double that of theoretical estimates of tropospheric noise [96] further suggests that the temporal resolution of GWMs, particularly in the Telica region, is critical for capturing stratified and turbulent tropospheric phase delays. All of the zenith total delay maps created in this study follow the same general approach, with the main difference being the methods used to interpolate the zenith total delay maps. The most obvious deviations between the uncorrected and GWM total delay maps were observed at Telica. It is possible that the ITD approach used to interpolate the HRES ECWMF zenith delay maps is less well-suited in regions with rapidly varying topography, and thus is unable to capture the components of the tropospheric noise accurately in the Telica region.

Our results suggest that the highest temporal resolution GWM tested, ERA5, performed best at Telica. At Masaya, GACOS slightly outperformed ERA5, but this may be more a function of the differences between the climate regions and satellite acquisition time in the early morning at Masaya compared to in the early evening at Telica. We however note that none of the applied tropospheric correction methods were able to consistently reduce the tropospheric phase delays at both case study sites. We encourage users to exert caution when deciding to use the results from a particular correction method as the corrected data can still contain significant errors introduced by the correction (e.g., Table 3, and Figures $4 \mathrm{~b}$ and $5 b$ ). Future work for capturing and removing the turbulent atmospheric phase delays may include approaches such as integrating the refractivity directly into the LOS direction as opposed to converting into LOS after computing the zenith total delay [36,48], or a combination of tropospheric phase delays predicted by multiple weather models and/or estimates of GPS zenith total delay or empirical phase-elevation based relations [21,29,54].

\section{Conclusions}

Obtaining accurate measurements of ground displacements is critical in active volcanic regions. Tropospheric phase delays greatly influence the observed displacement field obtained from InSAR studies, and various empirical and predictive methods are used in order to account for these phase delays. We examine the applicability of a linear empirical method and three Global Weather Models (GWMs), NARR, ERA5, and HRES ECMWF, with temporal resolutions between 1-6 h and horizontal spatial resolutions between $14-32 \mathrm{~km}$, to correct for tropospheric phase delays in two volcanic regions of Nicaragua. While ERA5 appears to perform best over the Telica region, and GACOS slightly outperforming ERA5 over the Masaya region, none of the tested tropospheric correction methods were able to accurately capture and significantly reduce the atmospheric noise within our case study regions. Instead, they often introduced more noise into the corrected results. Our study highlights the need for 
GWMs with higher temporal resolution (i.e., hourly or higher), particularly in regions where there is a greater degree of turbulent atmospheric phase delays. Care must be taken to avoid using averages of statistical measures as the only form of validation for which tropospheric correction model performs better (such as standard deviation, variance, or variance reduction). Outliers identified through the statistical assessments after corrections have been applied should be carefully examined, particularly in terms of whether the tropospheric correction method is either removing or adding noise to associated interferograms, prior to further analyses (e.g., time-series analysis or modeling).

Supplementary Materials: A Supplementary Materials document is available online at http://www.mdpi.com/ 2072-4292/12/5/782/s1.

Author Contributions: Conceptualization, C.W.; Data curation, K.J.S., R.C.B., M.H. and P.C.L.; Formal analysis, K.J.S.; Funding acquisition, C.W. and P.C.L.; Methodology, K.J.S. and C.W.; Project administration, K.J.S. and C.W.; Supervision, C.W. Visualization, K.J.S.; Writing—original draft, K.J.S., C.W. and R.C.B.; Writing—review \& editing, K.J.S., C.W., R.C.B., M.H. and P.C.L. All authors have read and agreed to the published version of the manuscript.

Funding: This study was funded by National Aeronautics and Space Administration (NASA) Earth Surface and Interior (ESI) grants (NNX17AD70G) to P.C.L. and C.W., (ESI NNX16AK87G) to C.W., and NSF (EAR-0911546) to P.C.L.

Acknowledgments: All SAR COSMO-SkyMed data obtained over Masaya and Telica were provided through the Committee on Earth Observation Satellites (CEOS) Volcano Pilot and Demonstrator working group programs (http://ceos.org/ourwork/workinggroups/disasters/volcanoes/). TanDEM-X $12 \mathrm{~m}$ resolution data were obtained through the German Aerospace Center (DLR Proposal ID 1552). ERA5 ECMWF weather reanalysis datasets were obtained through the Copernicus Climate Change Service (C3S) online Data Store (https://cds.climate. copernicus.eu/cdsapp\#!/home). HRES ECWMF zenith total delay maps were obtained through GACOS (http: //ceg-research.ncl.ac.uk/v2/gacos/) and provided MATLAB scripts for applying delay maps to interferograms were further modified to handle GAMMA interferograms and other functionalities by the authors. Neither the European Commission nor ECMWF is responsible for any use that may be made of the Copernicus Information or Data contained in this manuscript. NARR NCEP Reanalysis data were provided online by the NOAA/OAR/ESRL PSD, Boulder, Colorado, USA (https://www.esrl.noaa.gov/psd/). MATLAB scripts for creating and applying NARR phase screens were kindly provided by Amy Parker (CSIRO Australia) and were also modified by the authors for creating and applying ERA5 phase screens to CSK data. Additionally, SBAS MATLAB original scripts were kindly provided by Susanna Ebmeier (Leeds University) and further modified to handle GAMMA interferograms and other functionalities by the authors. MATLAB code for computation of variograms was obtained and modified from "MATLAB ${ }^{\circledR}$ Recipes for Earth Sciences" $(2015,4$ ed) by Martin H. Trauth. GMT6 was used to produce one figure [98]. Finally, this work was also conducted as part of the "Optimizing satellite resources for the global assessment and mitigation of volcanic hazards" Working Group supported by the John Wesley Powell Center for Analysis and Synthesis, funded by the U.S. Geological Survey. Authors would like to thank Romain Jolivet, Angélique Benoit, Kenneth Davis, Travis Tasker, Chuck Ammon, Raphäel Grandin, Francisco Delgado, Juliet Biggs, Fabien Albino, and Rowena Lohman for their helpful discussions and insight into weather models, time-series analysis and statistical assessment techniques, and Judit Gonzales-Santana and Sam Poppe for proof-reading later drafts of the manuscript. The authors would also like to thank five anonymous reviewers and the editor for their comments and suggestions which have helped to greatly improve this manuscript.

Conflicts of Interest: The authors declare no conflict of interest.

\section{Abbreviations}

The following abbreviations are used in this manuscript:

$\begin{array}{ll}\text { CAVA } & \text { Central American Volcanic Arc } \\ \text { CSK } & \text { COSMO-SkyMed } \\ \text { ECMWF } & \text { European Center for Medium-Range Weather Forecasts } \\ \text { ERA-I } & \text { ERA-Interim } \\ \text { GACOS } & \text { Generic Atmospheric Corrections Online Service for InSAR } \\ \text { GPS } & \text { Global Positioning System } \\ \text { GWM } & \text { Global Weather Model } \\ \text { HRES ECMWF } & \text { High-RESolution European Center for Medium-Range Weather Forecasts } \\ \text { INETER } & \text { Instituto Nicaragüense de Estudios Territoriales } \\ \text { InSAR } & \text { Interferometric Synthetic Aperture Radar }\end{array}$




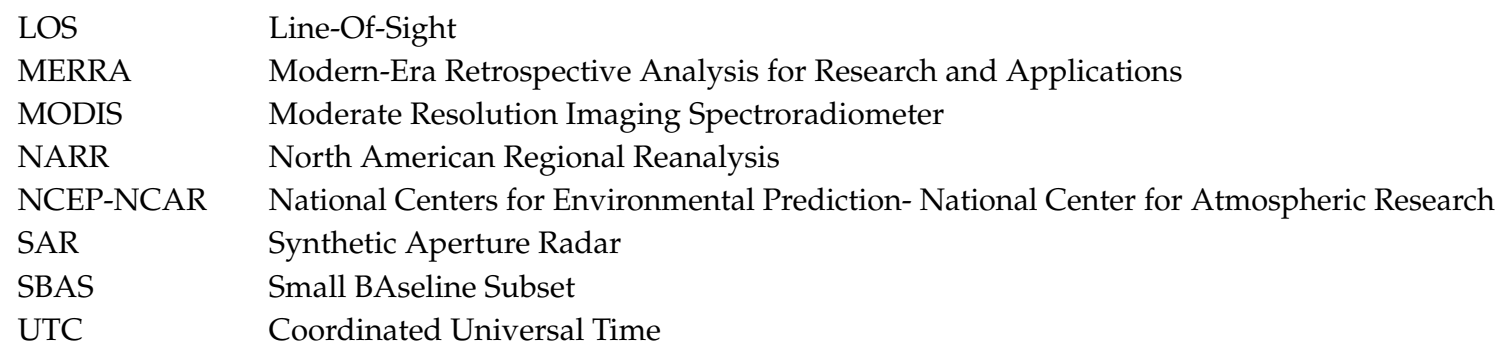

\section{References}

1. Burgmann, R.; Rosen, P.A.; Fielding, E.J. Synthetic Aperture Radar Interferometry to Measure Earth's Surface Topography and Its Deformation. Annu. Rev. Earth Planet. Sci. 2000, 28, 169-209. [CrossRef]

2. Pinel, V.; Poland, M.P.; Hooper, A. Volcanology: Lessons Learned from Synthetic Aperture Radar Imagery. J. Volcanol. Geotherm. Res. 2014, 289, 81-113. [CrossRef]

3. Fernández, J.; Pepe, A.; Poland, M.P.; Sigmundsson, F. Volcano Geodesy: Recent Developments and Future Challenges. J. Volcanol. Geotherm. Res. 2017, 344, 1-12. [CrossRef]

4. Ebmeier, S.K.; Andrews, B.J.; Araya, M.C.; Arnold, D.W.D.; Biggs, J.; Cooper, C.; Cottrell, E.; Furtney, M.; Hickey, J.; Jay, J.; et al. Synthesis of Global Satellite Observations of Magmatic and Volcanic Deformation: Implications for Volcano Monitoring \& the Lateral Extent of Magmatic Domains. J. Appl. Volcanol. 2018, 7, 26. [CrossRef]

5. Stephens, K.J.; Wauthier, C. Satellite Geodesy Captures Offset Magma Supply Associated with Lava Lake Appearance at Masaya Volcano, Nicaragua. Geophys. Res. Lett. 2018, 45, 2669-2678. [CrossRef]

6. Neal, C.A.; Brantley, S.R.; Antolik, L.; Babb, J.L.; Burgess, M.; Calles, K.; Cappos, M.; Chang, J.C.; Conway, S.; Desmither, L.; et al. The 2018 Rift Eruption and Summit Collapse of Kilauea Volcano. Science 2019, 363, 367-374. [CrossRef]

7. Smets, B.; Wauthier, C.; D'Oreye, N. A New Map of the Lava Flow Field of Nyamulagira (D.R. Congo) from Satellite Imagery. J. Afr. Earth Sci. 2010, 58, 778-786. [CrossRef]

8. Ebmeier, S.K.; Biggs, J.; Mather, T.A.; Elliott, J.R.; Wadge, G.; Amelung, F. Measuring Large Topographic Change with InSAR: Lava Thicknesses, Extrusion Rate and Subsidence Rate at Santiaguito Volcano, Guatemala. Earth Planet. Sci. Lett. 2012, 335, 216-225. [CrossRef]

9. Montgomery-Brown, E.K.; Poland, M.P.; Miklius, A. Delicate Balance of Magmatic-tectonic Interaction at Kilauea Volcano, Hawaii, Revealed from Slow Slip Events. In Hawaiian Volcanoes: From Source to Surface, Geophysical Monograph 208; Carey, R., Cayol, V., Poland, M.P., Weis, D., Eds.; John Wiley \& Sons, Inc.: Hoboken, NJ, USA, 2015; pp. 269-288. [CrossRef]

10. Schaefer, L.N.; Wang, T.; Escobar-Wolf, R.; Oommen, T.; Lu, Z.; Kim, J.; Lundgren, P.R.; Waite, G.P. Three-Dimensional Displacements of a Large Volcano Flank Movement during the May 2010 Eruptions at Pacaya Volcano, Guatemala. Geophys. Res. Lett. 2017, 44, 135-142. [CrossRef]

11. Arnold, D.W.D.; Biggs, J.; Dietterich, H.R.; Vallejo Vargas, S.; Wadge, G.; Mothes, P. Lava Flow Morphology at an Erupting Andesitic Stratovolcano: A Satellite Perspective on El Reventador, Ecuador. J. Volcanol. Geotherm. Res. 2019, 372, 34-47. [CrossRef]

12. Hanssen, R.F. Radar Interferometry-Data Interpretation and Error Analysis; Kluwer Academic Publishers: Dordrecht, The Netherlands, 2001.

13. Massonnet, D.; Feigl, K.L. Radar Interferometry and Its Application to Changes in the Earth's Surface. Rev. Geophys. 1998, 36, 441. [CrossRef]

14. Zebker, H.A.; Villasenor, J. Decorrelation in Interferometric Radar Echoes. IEEE Trans. Geosci. Remote Sens. 1992, 30, 950-959. [CrossRef]

15. Simons, M.; Rosen, P.A. Interferometric Synthetic Aperture Radar Geodesy. In Treatise on Geophysics; Schubert, G., Ed.; Elsevier: Oxford, UK, 2015; Volume 3, pp. 339-385. [CrossRef]

16. Böhm, J.; Schuh, H. (Eds.) Atmospheric Effects in Space Geodesy; Springer: Berlin/Heidelberg, Germany, 2013. [CrossRef]

17. Gray, A.L.; Mattar, K.E.; Sofko, G. Influence of Ionospheric Electron Density Fluctuations on Satellite Radar Interferometry. Geophys. Res. Lett. 2000, 27, 1451-1454. [CrossRef] 
18. Fattahi, H.; Simons, M.; Agram, P. InSAR Time-Series Estimation of the Ionospheric Phase Delay: An Extension of the Split Range-Spectrum Technique. IEEE Trans. Geosci. Remote Sens. 2017, 55, 5984-5996. [CrossRef]

19. Delacourt, C.; Briole, P.; Achache, J. Tropospheric Corrections of SAR Interferograms with Strong Topography. Application to Etna. Geophys. Res. Lett. 1998, 25, 2849-2852. [CrossRef]

20. Zebker, H.A.; Rosen, P.A.; Hensley, S. Atmospheric Effects in Interferometric Synthetic Aperture Radar Surface Deformation and Topographic Maps. J. Geophys. Res. 1997, 102, 7547-7563. [CrossRef]

21. Dong, J.; Zhang, L.; Liao, M.; Gong, J. Improved Correction of Seasonal Tropospheric Delay in InSAR Observations for Landslide Deformation Monitoring. Remote Sens. Environ. 2019, 233, 111370. [CrossRef]

22. Danklmayer, A.; Chandra, M. Precipitation Induced Signatures in SAR Images. In Proceedings of the 3rd European Conference on Antennas and Propagation, EuCAP 2009, Berlin, Germany, 23-27 March 2009; IEEE: Berlin, Germany, 2009; pp. 3433-3437.

23. Beauducel, F.; Briole, P.; Froger, J.-L. Volcano-Wide Fringes in ERS Synthetic Aperture Radar Interferograms of Etna (1992-1998): Deformation or Tropospheric Effect? J. Geophys. Res. 2000, 105, 16391-16402. [CrossRef]

24. Wicks, C.W., Jr.; Dzurisin, D.; Ingebritsen, S.; Thatcher, W.; Lu, Z.; Iverson, J. Magmatic Activity beneath the Quiescent Three Sisters Volcanic Center, Central Oregon Cascade Range, USA. Geophys. Res. Lett. 2002, 29, 26-1-26-4. [CrossRef]

25. Cavalié, O.; Doin, M.P.; Lasserre, C.; Briole, P. Ground Motion Measurement in the Lake Mead Area, Nevada, by Differential Synthetic Aperture Radar Interferometry Time Series Analysis: Probing the Lithosphere Rheological Structure. J. Geophys. Res. 2007, 112. [CrossRef]

26. Lin, Y.N.N.; Simons, M.; Hetland, E.A.; Muse, P.; DiCaprio, C. A Multiscale Approach to Estimating Topographically Correlated Propagation Delays in Radar Interferograms. Geochem. Geophys. Geosyst. 2010, 11. [CrossRef]

27. Bekaert, D.P.S.; Walters, R.J.; Wright, T.J.; Hooper, A.J.; Parker, D.J. Statistical Comparison of InSAR Tropospheric Correction Techniques. Remote Sens. Environ. 2015, 170, 40-47. [CrossRef]

28. Bekaert, D.P.S.; Hooper, A.J.; Wright, T.J. A Spatially Variable Power Law Tropospheric Correction Technique for InSAR Data. J. Geophys. Res. 2015, 120, 1345-1356. [CrossRef]

29. Murray, K.D.; Bekaert, D.P.S.; Lohman, R.B. Tropospheric Corrections for InSAR: Statistical Assessments and Applications to the Central United States and Mexico. Remote Sens. Environ. 2019, 232, 111326. [CrossRef]

30. Bevis, M.; Businger, S.; Herring, T.A.; Rocken, C.; Anthes, R.A.; Ware, R.H. GPS Meteorology: Remote Sensing of Atmospheric Water Vapor Using the Global Positioning System. J. Geophys. Res. 1992, 97, 15787-15801. [CrossRef]

31. Doin, M.-P.; Lasserre, C.; Peltzer, G.; Cavalié, O.; Doubre, C. Corrections of Stratified Tropospheric Delays in SAR Interferometry: Validation with Global Atmospheric Models. J. Appl. Geophys. 2009, 69, 35-50. [CrossRef]

32. Jolivet, R.; Grandin, R.; Lasserre, C.; Doin, M.-P.; Peltzer, G. Systematic InSAR Tropospheric Phase Delay Corrections from Global Metereological Reanalysis Data. Geophys. Res. Lett. 2011, 38. [CrossRef]

33. Jolivet, R.; Agram, P.S.; Lin, N.Y.; Simons, M.; Doin, M.-P.; Peltzer, G.; Li, Z. Improving InSAR Geodesy Using Global Atmospheric Models. J. Geophys. Res. Solid Earth 2014, 119, 2324-2341. [CrossRef]

34. Parker, A.L.; Biggs, J.; Walters, R.J.; Ebmeier, S.K.; Wright, T.J.; Teanby, N.A.; Lu, Z. Systematic Assessment of Atmospheric Uncertainties for InSAR Data at Volcanic Arcs Using Large-Scale Atmospheric Models: Application to the Cascade Volcanoes, United States. Remote Sens. Environ. 2015, 170, 102-114. [CrossRef]

35. Stephens, K.J.; Ebmeier, S.K.; Young, N.K.; Biggs, J. Transient Deformation Associated with Explosive Eruption Measured at Masaya Volcano (Nicaragua) Using Interferometric Synthetic Aperture Radar. J. Volcanol. Geotherm. Res. 2017, 344, 212-223. [CrossRef]

36. Cong, X.; Balss, U.; Gonzalez, F.R.; Eineder, M. Mitigation of Tropospheric Delay in SAR and InSAR Using NWP Data: Its Validation and Application Examples. Remote Sens. 2018, 10, 1515. [CrossRef]

37. Samsonov, S.V.; Trishchenko, A.P.; Tiampo, K.; González, P.J.; Zhang, Y.; Fernández, J. Removal of Systematic Seasonal Atmospheric Signal from Interferometric Synthetic Aperture Radar Ground Deformation Time Series. Geophys. Res. Lett. 2014, 41, 6123-6130. [CrossRef]

38. Heleno, S.I.N.; Frischknecht, C.; D’Oreye, N.; Lima, J.N.P.; Faria, B.; Wall, R.; Kervyn, F. Seasonal Tropospheric Influence on SAR Interferograms near the ITCZ-The Case of Fogo Volcano and Mount Cameroon. J. Afr. Earth Sci. 2010, 58, 833-856. [CrossRef] 
39. Li, Z.; Fielding, E.J.; Cross, P.; Preusker, R. Advanced InSAR Atmospheric Correction: MERIS/MODIS Combination and Stacked Water Vapour Models. Int. J. Remote Sens. 2009, 30, 3343-3363. [CrossRef]

40. Wadge, G.; Webley, P.W.; James, I.N.; Bingley, R.; Dodson, A.; Waugh, S.; Veneboer, T.; Puglisi, G.; Mattia, M.; Baker, D.; et al. Atmospheric Models, GPS and InSAR Measreuments of the Tropospheric Water Vapour Field over Mount Etna. Geophys. Res. Lett. 2002, 29, 11-1-11-4. [CrossRef]

41. Webley, P.W.; Wadge, G.; James, I.N. Determining Radio Wave Delay by Non-Hydrostatic Atmospheric Modelling of Water Vapour over Mountains. Phys. Chem. Earth 2004, 29, 139-148. [CrossRef]

42. Foster, J.; Brooks, B.; Cherubini, T.; Shacat, C.; Businger, S.; Werner, C.L. Mitigating Atmospheric Noise for InSAR Using a High Resolution Weather Model. Geophys. Res. Lett. 2006, 33. [CrossRef]

43. Li, Z.; Muller, J.-P.; Cross, P.; Fielding, E.J. Interferometric Synthetic Aperture Radar (InSAR) Atmospheric Correction: GPS, Moderate Resolution Imaging Spectrometer (MODIS), and InSAR Integration. J. Geophys. Res. 2005, 110. [CrossRef]

44. Yu, C.; Li, Z.; Penna, N.T.; Crippa, P. Generic Atmospheric Correction Model for Interferometric Synthetic Aperture Radar Observations. J. Geophys. Res. Solid Earth 2018, 12, 9202-9222. [CrossRef]

45. Pinel, V.; Hooper, A.; De la Cruz-Reyna, S.; Reyes-Davila, G.; Doin, M.P.; Bascou, P. The Challenging Retrieval of the Displacement Field from InSAR Data for Andesitic Stratovolcanoes: Case Study of Popocatepetl and Colima Volcano, Mexico. J. Volcanol. Geotherm. Res. 2011, 200, 49-61. [CrossRef]

46. Welch, M.D.; Schmidt, D.A. Separating Volcanic Deformation and Atmospheric Signals at Mount St. Helens Using Persistent Scatterer InSAR. J. Volcanol. Geotherm. Res. 2017, 344, 52-64. [CrossRef]

47. Neelmeijer, J.; Schöne, T.; Dill, R.; Klemann, V.; Motagh, M. Ground Deformations around the Toktogul Reservoir, Kyrgyzstan, from Envisat ASAR and Sentinel-1 Data-A Case Study about the Impact of Atmospheric Corrections on InSAR Time Series. Remote Sens. 2018, 10, 462. [CrossRef]

48. Hu, Z.; Mallorquí, J.J. An Accurate Method to Correct Atmospheric Phase Delay for InSAR with the ERA5 Global Atmospheric Model. Remote Sens. 2019, 11, 1969. [CrossRef]

49. Albino, F.; Biggs, J.; Syahbana, D.K. Dyke Intrusion between Neighbouring Arc Volcanoes Responsible for 2017 Pre-Eruptive Seismic Swarm at Agung. Nat. Commun. 2019, 10. [CrossRef] [PubMed]

50. Guo, Q.; Xu, C.; Wen, Y.; Liu, Y.; Xu, G. The 2017 Noneruptive Unrest at the Caldera of Cerro Azul Volcano (Galápagos Islands) Revealed by InSAR Observations and Geodetic Modelling. Remote Sens. 2019, 11, 1992. [CrossRef]

51. Wang, X.; Aoki, Y. Posteruptive Thermoelastic Deflation of Intruded Magma in Usu Volcano, Japan, 1992-2017. J. Geophys. Res. Solid Earth 2019, 124, 335-357. [CrossRef]

52. Wang, Q.; Yu, W.; Xu, B.; Wei, G. Assessing the Use of GACOS Products for SBAS-InSAR Deformation Monitoring: A Case in Southern California. Sensors 2019, 19, 3894. [CrossRef]

53. Yip, S.T.H.; Biggs, J.; Albino, F. Reevaluating Volcanic Deformation Using Atmospheric Corrections: Implications for the Magmatic System of Agung Volcano, Indonesia. Geophys. Res. Lett. 2019, 46, 1-8. [CrossRef]

54. Albino, F.; Biggs, J.; Yu, C.; Li, Z. Automated Methods for Detecting Volcanic Deformation Using Sentinel-1 InSAR Time Series Illustrated by the 2017-2018 Unrest at Agung, Indonesia. J. Geophys. Res. Solid Earth 2020. [CrossRef]

55. Lundgren, P.; Usai, S.; Sansosti, E.; Lanari, R.; Tesauro, M.; Fornaro, G.; Berardino, P. Modeling Surface Deformation Observed with Synthetic Aperture Radar Interferometry at Campi Flegrei Caldera. J. Geophys. Res. 2001, 106, 19355-19366. [CrossRef]

56. Berardino, P.; Fornaro, G.; Lanari, R.; Sansosti, E. A New Algorithm for Surface Deformation Monitoring Based on Small Baseline Differential SAR Interferograms. IEEE Trans. Geosci. Remote Sens. 2002, 40, 2375-2383. [CrossRef]

57. Werner, C.; Wegmüller, U.; Strozzi, T.; Wiesmann, A. GAMMA SAR and Interferometric Processing Software. ERS-ENVISAT Symposium, Gothenburg, Sweden. 2000. Available online: http:/citeseerx.ist.psu.edu/ viewdoc/download?doi=10.1.1.20.6363\&rep=rep1\&type=pdf (accessed on 1 March 2020).

58. Rizzoli, P.; Martone, M.; Gonzalez, C.; Wecklich, C.; Borla Tridon, D.; Bräutigam, B.; Bachmann, M.; Schulze, D.; Fritz, T.; Huber, M.; et al. Generation and Performance Assessment of the Global TanDEM-X Digital Elevation Model. ISPRS J. Photogramm. Remote Sens. 2017, 132, 119-139. [CrossRef] 
59. Wessel, B.; Huber, M.; Wolfhart, C.; Marschalk, U.; Kosmann, D.; Roth, A. Accuracy Assessment of the Global TanDEM-X Digital Elevation Model with GPS Data. ISPRS J. Photogramm. Remote Sens. 2018, 139, 171-182. [CrossRef]

60. Goldstein, R.M.; Werner, C.L. Radar Interferogram Filtering for Geophysical Applications. Geophys. Res. Lett. 1998, 25, 4035-4038. [CrossRef]

61. Costantini, M. A Novel Phase Unwrapping Method Based on Network Programming. IEEE Trans. Geosci. Remote Sens. 1998, 36, 813-821. [CrossRef]

62. Zumberge, J.F.; Heflin, M.B.; Jefferson, D.C.; Watkins, M.M.; Webb, F.H. Precise Point Positioning for the Efficient and Robust Analysis of GPS Data from Large Networks. J. Geophys. Res. 1997, 102, 5005-5017. [CrossRef]

63. Bertiger, W.; Desai, S.D.; Haines, B.; Harvey, N.; Moore, A.W.; Owen, S.; Weiss, J.P. Single Receiver Phase Ambiguity Resolution with GPS Data. J. Geod. 2010, 84, 327-337. [CrossRef]

64. Lyard, F.; Lefevre, F.; Letellier, T.; Francis, O. Modelling the Global Ocean Tides: Modern Insights from FES2004. Ocean Dyn. 2006, 56, 394-415. [CrossRef]

65. Boehm, J.; Werl, B.; Schuh, H. Troposphere Mapping Functions for GPS and Very Long Baseline Interferometry from European Centre for Medium-Range Weather Forecasts Operational Analysis Data. J. Geophys. Res. 2006, 111, B02406. [CrossRef]

66. Rebischung, P.; Griffiths, J.; Ray, J.; Schmid, R.; Collilieux, X.; Garayt, B. IGS08: The IGS Realization of ITRF2008. GPS Solut. 2012, 16, 483-494. [CrossRef]

67. Fialko, Y.; Simons, M.; Agnew, D. The Complete (3-D) Surface Displacement Field in the Epicentral Area of the 1999 Mw 7.1 Hector Mine Earthquake, California from Space Geodetic Observations. Geophys. Res. Lett. 2001, 28, 3063-3066. [CrossRef]

68. Mesinger, F.; DiMego, G.; Kalnay, E.; Mitchell, K.; Shafran, P.C.; Ebisuzaki, W.; Jović, D.; Woollen, J.; Rogers, E.; Berbery, E.H.; et al. North American Regional Reanalysis. Bull. Am. Meteorol. Soc. 2006, 87, 343-360. [CrossRef]

69. Rogers, E.; Lin, Y.; Mitchell, K.; Wu, W.-S.; Ferrier, B.; Gayno, G.; Pondeca, M.; Pyle, M.; Wong, V.; Ek, M. The NCEP North American Modeling System: Final Eta Model Analysis Changes and Preliminary Experiments Using the WRF-NMM. In Proceedings of the 21st Conference on Weather Analysis and Forecasting/17th Conference on Numerical Weather Prediction; American Meteorological Society; Washington, DC, USA, 2005.

70. Copernicus Climate Change Service (C3S). ERA5: Fifth Generation of ECMWF Atmospheric Reanalysis of the Global Climate. 2017. Available online: https://cds.climate.copernicus.eu/cdsapp\#!/home (accessed on 1 March 2020).

71. Hersbach, H.; De Rosnay, P.; Bell, B.; Schepers, D.; Simmons, A.; Soci, C.; Abdalla, S.; Balmaseda, A.; Balsamo, G.; Bechtold, P.; et al. Operational Global Reanalysis: Progress, Future Directions and Synergies with NWP Including Updates on the ERA5 Production Status. ERA Rep. Ser. 2018. [CrossRef]

72. Baby, H.B.; Gole, P.; Lavergnat, J. A Model for the Tropospheric Excess Path Length of Radio Waves from Surface Meteorological Measurements. Radio Sci. 1988, 23, 1023-1038. [CrossRef]

73. Smith, E.K.; Weintraub, S. The Constants in the Equation for Atmospheric Refractive Index at Radio Frequencies. Proc. IRE 1952, 41, 1035-1037. [CrossRef]

74. Yu, C.; Penna, N.T.; Li, Z. Generation of Real-Time Mode High-Resolution Water Vapor Fields from GPS Observations. J. Geophys. Res. Atmos. 2017, 122, 2008-2025. [CrossRef]

75. Yu, C.; Li, Z.; Penna, N.T. Interferometric Synthetic Aperture Radar Atmospheric Correction Using a GPS-Based Iterative Tropospheric Decomposition Model. Remote Sens. Environ. 2018, 204, 109-121. [CrossRef]

76. Ebmeier, S.K.; Biggs, J.; Mather, T.A.; Amelung, F. On the Lack of InSAR Observations of Magmatic Deformation at Central American Volcanoes. J. Geophys. Res. Solid Earth 2013, 118, 2571-2585. [CrossRef]

77. Ebmeier, S.K.; Biggs, J.; Mather, T.A.; Amelung, F. Applicability of InSAR to Tropical Volcanoes: Insights from Central America. Geol. Soc. Lond. Spec. Publ. 2013, 380, 15-37. [CrossRef]

78. Peel, M.C.; Finlayson, B.L.; McMahon, T.A. Updated World Map of the Köppen-Geiger Climate Classification. Hydrol. Earth Syst. Sci. 2007, 11, 1633-1644. [CrossRef]

79. Global Volcanism Program. Telica (344040). Volcanoes of the World. 2013. Available online: https: //volcano.si.edu/volcano.cfm?vn=344040 (accessed on 1 March 2020). 
80. Geirsson, H.; Rodgers, M.; LaFemina, P.; Witter, M.; Roman, D.; Muñoz, A.; Tenorio, V.; Alvarez, J.; Jacobo, V.C.; Nilsson, D.; et al. Multidisciplinary Observations of the 2011 Explosive Eruption of Telica Volcano, Nicaragua: Implications for the Dynamics of Low-Explosivity Ash Eruptions. J. Volcanol. Geotherm. Res. 2014, 271, 55-69. [CrossRef]

81. Roman, D.C.; LaFemina, P.C.; Bussard, R.; Stephens, K.J.; Wauthier, C.; Higgins, M.; Feineman, M.; Arellano, S.; de Moor, J.M.; Avard, G.; et al. Mechanisms of Unrest and Eruption at Persistently Restless Volcanoes: Insights from the 2015 Eruption of Telica Volcano, Nicaragua. Geochem. Geophys. Geosyst. 2019, 20, 4162-4183. [CrossRef]

82. Global Volcanism Program. Volcanoes of the World. v. 4.8.0. 2013. Available online: https://doi.org/10.5479/ si.GVP.VOTW4-2013 (accessed on 1 March 2020).

83. World Population Review. Population of Cities in Nicaragua. 2019. Available online: http: //worldpopulationreview.com/countries/nicaragua-population/cities/ (accessed on 25 August 2019).

84. Global Volcanism Program. Masaya (344100). Volcanoes of the World. 2013. Available online: https: //volcano.si.edu/volcano.cfm?vn=344100 (accessed on 1 March 2020). [CrossRef]

85. McBirney, A.R. The Nicaraguan Volcano Masaya and Its Caldera. EOS Trans. Am. Geophys. Union 1956, 37, 83-96. [CrossRef]

86. Bice, D. Tephra Stratigraphy and Physical Aspects of Recent Volcanism near Managua, Nicaragua. Ph.D. Thesis, University of California, Berkeley, CA, USA, 1980.

87. Kutterolf, S.; Freundt, A.; Pérez, W.; Wehrmann, H.; Schmincke, H.U. Late Pleistocene to Holocene Temporal Succession and Magnitudes of Highly-Explosive Volcanic Eruptions in West-Central Nicaragua. J. Volcanol. Geotherm. Res. 2007, 163, 55-82. [CrossRef]

88. Rymer, H.; van Wyk de Vries, B.; Stix, J.; Williams-Jones, G. Pit Crater Structure and Processes Governing Persistent Activity at Masaya Volcano, Nicaragua. Bull. Volcanol. 1998, 59, 345-355. [CrossRef]

89. Stoiber, R.E.; Williams, S.N.; Huebert, B.J. Sulfur and Halogen Gases at Masaya Caldera Complex, Nicaragua: Total Flux and Variaations with Time. J. Geophys. Res. 1986, 91, 12215-12231. [CrossRef]

90. INETER. Boletín Mensual Sismos y Volcanes de Nicaragua, Diciembre 2015. 2015. Available online: http://webserver2.ineter.gob.ni/boletin/2015/12/index1512.htm (accessed on 1 March 2020).

91. INETER. Boletín Mensual: Sismos y Volcanes de Nicaragua, Octubre 2006. 2006. Available online: https://webserver2.ineter.gob.ni//boletin/2006/10/volcan-masaya0610.htm (accessed on 1 March 2020).

92. Murray, J.; Caravantes Gonzalez, G.; Rymer, H.; Williams-Jones, G.; Ferrucci, F. Recent Inflation at Masay Volcano, Nicaragua. In IAVCEI 2017 Scientific Assembly: Fostering Integrative Studies of Volcanoes; IAVCEI: Portland, OR, USA, 2017; p. 739.

93. Rymer, H.; Williams-Jones, G.; Murray, J.; Delmelle, P.; Reid, K.; Caravantes Gonzalez, G. Precursors to the Current Activity at Masaya Volcano, Nicaragua. In IAVCEI 2017 Scientific Assembly: Fostering Integrative Studies of Volcanoes; IAVCEI: Portland, OR, USA, 2017; p. 939.

94. Aiuppa, A.; de Moor, J.M.; Arellano, S.; Coppola, D.; Francofonte, V.; Galle, B.; Giudice, G.; Liuzzo, M.; Mendoza, E.; Saballos, A.; et al. Tracking Formation of a Lava Lake from Ground and Space: Masaya Volcano (Nicaragua), 2014-2017. Geochem. Geophys. Geosyst. 2018, 19, 496-515. [CrossRef]

95. De Moor, J.M.; Kern, C.; Avard, G.; Muller, C.; Aiuppa, A.; Saballos, A.; Ibarra, M.; LaFemina, P.; Protti, M.; Fischer, T.P. A New Sulfur and Carbon Degassing Inventory for the Southern Central American Volcanic Arc: The Importance of Accurate Time-Series Datasets and Possible Tectonic Processes Responsible for Temporal Variations in Arc-Scale Volatile Emissions. Geochem. Geophys. Geosyst. 2017, 18, 4437-4468. [CrossRef]

96. Emardson, T.R.; Simons, M.; Webb, F.H. Neutral Atmospheric Delay in Interferometric Synthetic Aperture Radar Applications: Statistical Description and Mitigation. J. Geophys. Res. 2003, 108. [CrossRef]

97. Jolivet, R.; Lasserre, C.; Doin, M.P.; Guillaso, S.; Peltzer, G.; Dailu, R.; Sun, J.; Shen, Z.K.; Xu, X. Shallow Creep on the Haiyuan Fault (Gansu, China) Revealed by SAR Interferometry. J. Geophys. Res. 2012, 117. [CrossRef]

98. Wessel, P.; Smith, W.H.F. New, Improved Version of the Generic Mapping Tools Released. EOS Trans. Am. Geophys. Union 1998, 79, 579. [CrossRef]

(C) 2020 by the authors. Licensee MDPI, Basel, Switzerland. This article is an open access article distributed under the terms and conditions of the Creative Commons Attribution (CC BY) license (http://creativecommons.org/licenses/by/4.0/). 